\title{
A hypometabolic defense Strategy against PLASModium infeCtion
}

Susana Ramos ${ }^{{ }^{\star}}$, Temitope W. Ademolue ${ }^{1^{\star}}$, Elisa Jentho ${ }^{1,2}$, Qian $\mathrm{Wu}^{1}$, Joel Guerra ${ }^{2}$, Rui Martins ${ }^{1}$, Gil Pires ${ }^{1}$, Sebastian Weis ${ }^{2,3,4}$, Ana Rita Carlos ${ }^{1}$, Inês Mahú ${ }^{1}$, Elsa Seixas ${ }^{1}$, Denise Duarte ${ }^{5}$, Fabienne Rajas ${ }^{6}$, Sílvia Cardoso ${ }^{1}$, António G. G. Sousa ${ }^{1}$, Jingtao Lilue ${ }^{1}$, Gilles Mithieux ${ }^{6}$, Fátima Nogueira ${ }^{5}$ and Miguel P. Soares ${ }^{1,7 \#}$

${ }^{1}$ Instituto Gulbenkian de Ciência, Oeiras, Portugal.

2Department of Anesthesiology and Intensive Care Medicine, Jena University Hospital, Friedrich-Schiller-University, Jena, Germany.

${ }^{3}$ Institute for Infectious Disease and Infection Control, University Hospital Jena, Germany.

${ }^{4}$ Center for Sepsis Control and Care, Jena University, Germany.

${ }^{5}$ Global Health and Tropical Medicine, Instituto de Higiene e Medicina Tropical, Universidade NOVA de Lisboa, Lisboa, Portugal.

${ }^{6}$ Université Claude Bernard Lyon, INSERM, France.

${ }^{7}$ Lead Contact.

\#Correspondence: mpsoares@igc.gulbenkian.pt

${ }^{*}$ Equal contribution.

\section{SUMMARY}

Hypoglycemia is a clinical hallmark of severe malaria, the often-lethal presentation of Plasmodium falciparum infection of humans. Here we report that mice reduce blood glucose levels in response to Plasmodium infection via a coordinated response whereby labile heme, an alarmin produced via hemolysis, induces anorexia and represses hepatic glucose production (HGP). While protective against unfettered immune-mediated inflammation, organ damage and anemia, when sustained over time heme-driven repression of HGP can progress towards hypoglycemia, compromising host energy expenditure and thermoregulation. This hypometabolic state arrests the development of asexual stages of Plasmodium spp., which undergo pyknosis and develop mitochondrial dysfunction. In response, Plasmodium activates a transcriptional program reducing its virulence and inducing sexual differentiation towards the production of transmissible gametocytes. We infer that malariaassociated hypoglycemia represents a trade-off of an evolutionarily conserved defense strategy restricting Plasmodium spp. from accessing host-derived glucose and balancing parasite virulence and transmission.

KEYWORDS Infection; Malaria; Plasmodium; Hypoglycemia; Heme; Evolutionary Trade-Off, Virulence, Transmission. 


\section{INTRODUCTION}

Severe malaria refers to life-threatening clinical presentations of $P$. falciparum infection (Karnad et al., 2018; Marsh et al., 1995; Miller et al., 2002), in which hypoglycemia is a major independent risk factor of mortality (Madrid et al., 2015; Marsh et al., 1995; Service, 1995; White et al., 1983). The pathogenesis of malariaassociated hypoglycemia is thought to develop from a combination of events: anorexia of infection, an evolutionarily conserved component of sickness behavior that reduces appetite and nutrient intake from diet (Clark et al., 2008; Hart, 1988), as well as deregulation of hepatic glucose production (HGP)(Geoffrion et al., 1985; Kawo et al., 1990; Thien et al., 2006) and glucose consumption by Plasmodium spp. (Olszewski and Llinas, 2011; Preuss et al., 2012b; Thien et al., 2006) and immune cells (Buck et al., 2017; Man et al., 2017; Wang et al., 2019).

Whether malaria-associated hypoglycemia is a pathologic event per se or whether its pathologic effects represent a trade-off (Stearns and Medzhitov, 2015) of an otherwise adaptive response to Plasmodium spp. infection is unclear. Supporting its intrinsic pathologic nature, glucose administration to Plasmodium chabaudi chabaudi (Pcc)-infected mice is protective, while pharmacologic inhibition of glycolysis is detrimental (Cumnock et al., 2018). However, the reduction of blood glucose levels associated with caloric restriction (Mancio-Silva et al., 2017) or inhibition of glycolysis (Wang et al., 2018), are protective against $P$. berghei ANKAinfection in mice. Moreover, $P$. falciparum proliferation in vitro depends on glucose (Humeida et al., 2011) and reducing glucose concentration induces parasite pyknosis (Babbitt et al., 2012).

Malaria-associated hypoglycemia develops during the circadian cycles of parasite red blood cell (RBC) invasion, proliferation and hemolysis. Labile heme, an alarmin generated as a byproduct of hemolysis (Soares and Bozza, 2016) during the blood stage of Plasmodium spp. infection (Ademolue et al., 2017; Cruz et al., 2018; Elphinstone et al., 2016; Gouveia et al., 2017; Ramos et al., 2019) promotes the pathogenesis of severe malaria (Ferreira et al., 2008; Knackstedt et al., 2019; Pamplona et al., 2007). The pathologic effects of labile heme are countered by a host stress-responsive transcriptional program whereby the nuclear factor erythroid 2related factor 2 (NRF2) induces the heme catabolizing enzyme, heme oxygenase-1 (HO-1) (Ferreira et al., 2011; Pamplona et al., 2007; Ramos et al., 2019; Seixas et al., 2009). While protective against malaria, heme catabolism by HO-1 does not appear to impose a fitness cost on the development of asexual stages of Plasmodium spp., establishing disease tolerance to malaria (Ferreira et al., 2011; 
Ramos et al., 2019). This defense strategy underlies the protective effect of sickle hemoglobin $(\mathrm{Hb})$ against severe malaria (Ferreira et al., 2011).

Heme catabolism by $\mathrm{HO}-1$ produces catalytic iron that can repress the transcription of the hepatic gluconeogenic enzyme glucose-6-phosphatase catalytic subunit 1 (G6pc1) (Weis et al., 2017). Given the excessive amounts of labile heme that accumulate in plasma during Plasmodium spp. infection in mice (Gouveia et al., 2017; Ramos et al., 2019) and humans (Ademolue et al., 2017; Cruz et al., 2018; Elphinstone et al., 2016; Knackstedt et al., 2019), we hypothesized that labile heme might contribute to the development of malaria-associated hypoglycemia. Here, we demonstrate that labile heme is sufficient per se to recapitulate the development of anorexia, repression of HGP and reduction of glycemia, observed in response to PcC infection in mice. While protective against immune-mediated liver damage and anemia, sustained repression of HGP led to hypoglycemia, compromising the energetic demands of the infected host. This hypometabolic state is sensed by asexual stages of Plasmodium, which activate a transcriptional program associated with arrested development, reduction of virulence and sexual differentiation towards the production of transmissible gametocytes. These findings suggest that while labile heme elicits a protective hypometabolic response that imposes a fitness cost to Plasmodium, this defense strategy carries as a major trade-off the development of malaria-associated hypoglycemia, a defining feature of severe malaria.

\section{RESULTS:}

HGP CONTROLS GLYCEMIA DURING PLASMODIUM INFECTION (Fig. 1\&S1)

Intraperitoneal (i.p.) inoculation of Pcc AS-infected RBC (iRBCs) to C57BL/6 mice was characterized by increasing numbers of circulating $\mathrm{RBC}$ during the first 7 days (i.e. peak of infection), decreasing thereafter (Fig. 1A). This was associated with the development of severe anemia (Fig. 1A), anorexia and fasting during the peak of infection (Fig. 1B)(Cumnock et al., 2018; Elased and Playfair, 1994). Moreover, there was a marked reduction of blood glucose concentration (Fig. 1C), paralleled by the repression of hepatic G6pc1 mRNA (Fig. 1D) and protein (Fig. 1E) expression.

Administration of a pyruvate bolus (i.e. pyruvate tolerance test; PTT) to C57BL/6 mice at the peak of $P c c$ infection failed to increase glycemia to the level observed in control, fasted mice (Fig. 1F; S1A). Pyruvate is a preferential hepatic gluconeogenic substrate (Hughey et al., 2014), suggesting that PcC infection is associated with repression of HGP, as in human malaria (Thien et al., 2006). 
Administration of a glucose bolus (i.e. glucose tolerance test; GTT) to C57BL/6 mice at the peak of Pcc infection failed to increase blood glucose levels in infected mice to the levels observed in control, fasted mice (Fig. 1G). This is in line with an overall increase in glucose consumption, as in human malaria (Madrid et al., 2017; Thien et al., 2006; White et al., 1983).

Administration of an insulin bolus (i.e. insulin tolerance test; ITT) to C57BL/6 mice at the peak of $P c c$ infection reduced glycemia to a lower extent, compared to control fasted mice (Fig. 1H). Insulin administration to control fasted mice caused seizures, not observed in PCC-infected mice (Fig. S1B). This suggests that PCC-infected mice develop insulin resistance as a protective mechanism against "grand mal" seizures (Arieff et al., 1974).

To determine whether HGP controls glycemia during PcC infection (Fig. 1D), hepatic G6pc1 was deleted in an inducible manner in G6pc1 $1^{A l b \Delta / \Delta}$ mice (Mutel et al., 2011). Individual disease trajectories (Schneider, 2011), established by the relationship of glycemia and pathogen load, showed that Pcc-infected G6pc1 $1^{A l b \Delta / \Delta}$ mice developed lethal hypoglycemia (Fig. 1I-K; S1C), under similar pathogen loads to control G6pc1/f/fl mice (Fig. 1L). This suggests that HGP plays a central role in the regulation of glycemia during Pcc infection. Of note, insulin concentration in plasma was barely detectable at the peak of $P c c$-infection in $G 6 p c 1^{A / b \Delta / \Delta}$ or $G 6 p c 1^{f / / f l}$ mice (Fig. S1D), suggesting that insulin does not play a central role in the regulation of glycemia during Pcc infection.

The individual disease trajectories established by the relationship of core body temperature $v s$. pathogen load, revealed that the decrease in core body temperature was more pronounced in Pcc-infected G6pc1 $1^{A l b \Delta / \Delta} v s$. G6pc1 $1^{f / f l}$ mice (Fig. S1E-G). This was not the case for body weight loss (Fig. S1H-J), suggesting that HGP supports thermoregulation, while promoting body weight loss during Pcc infection.

\section{HGP CONTROLS HOSt ENERGy EXPENDITURE DURING PCC INFECTION (Fig. 2\&S2)}

Sustained repression of hepatic G6pc1 expression in $G 6 p c 1^{A / b \Delta / \Delta}$ mice was associated with a more pronounced reduction of energy expenditure (EE) in response to Pcc infection, compared to G6pc1 $1^{f / f l}$ mice (Fig. 2A,B). This could not be attributed to differences in daily food intake (Fig. 2C), which was reduced to the same extent in Pcc-infected G6pc1 $1^{A l b \Delta / \Delta}$ vs. G6pc1 $1^{f / / t l}$ mice (mg/day range), compared to non-infected genotype matched controls (Fig. S2D; i.e. g/day). Reduction of EE was instead associated with lower activity (i.e. lethargy) (Fig. 2D; S2A) and respiratory exchange ratio (RER), in Pcc-infected G6pc1 ${ }^{A l b \Delta / \Delta}$ vs. G6pc1 $1^{f / f t}$ mice (Fig. 
$2 E, F)$. The later was attributed to a decrease in the ratio of $\mathrm{CO}_{2}$ production $\left(\mathrm{VCO}_{2}\right)$ (Fig. 2G) vs. $\mathrm{O}_{2}$ consumption $\left(\mathrm{VO}_{2}\right)$ (Fig. 2H). This suggests that repression of HGP in response to PCC infection delineates the lower viable threshold of host glycemia without compromising vital metabolic processes. Of note, steady-state EE (Fig. $S 2 B, C$ ), food intake (Fig. S2D), RER (Fig. S2E,F), VCO 2 (Fig. S2G) and $\mathrm{VO}_{2}$ (Fig. $S 2 H)$ were similar in $G 6 p c 1^{A l b \Delta / \Delta}$ vs. G6pc $1^{f / f / t}$ mice.

\section{LABILE heme RECAPITULATES THE hyPOMETABOLIC RESPONSE ELICITED BY PCC} INFECTION (Fig. 2\&S2)

We asked whether the accumulation of labile heme contributes to the hypometabolic response to malaria. Heme administration to naïve C57BL/6 mice recapitulated the hallmarks of sickness behavior associated with Pcc infection, including anorexia (Fig. $2 I, J)$ and lethargy (Fig. 2K,L; S2I,J). Other components of the hypometabolic response to Pcc infection, including reduced EE (Fig. 2M,N) and RER (Fig. 2O,P), with the latter reflecting a decrease of $\mathrm{CO}_{2}$ production $\left(\mathrm{VCO}_{2}\right)$ vs. $\mathrm{O}_{2}$ consumption $\left(\mathrm{VO}_{2}\right)$ (Fig. S2K-M), were also induced in response to heme administration. Protoporphyrin IX (PPIX) lacking the iron atom present in heme (i.e. Feprotoporphyrin IX), did not induce any of these changes (Fig. 2I-P; S2I-M).

Consistent with labile heme repressing hepatic G6Pc1 in vivo (Weis et al., 2017), heme administration to fasted mice reduced the transient increase in glycemia in a PTT (Fig. S2O). This is in agreement with labile heme repressing HGP in vivo, similar to PcC infection.

\section{LABILE HEME RECAPITULATES THE REPRESSION OF HEPATIC GENE EXPRESSION IN RESPONSE TO PCC INFECTION (Fig. 3 \& S3)}

Considering the liver as a metabolic hub, beyond HGP, we asked whether labile heme exerts additional effects, contributing to the state of negative energy balance imposed by malaria. For that purpose, we analyzed bulk RNA-sequencing data from the livers of mice infected with $P c c$ or receiving heme. Fasted mice were used as controls to account for the development of anorexia in PCC-infected and hemetreated mice. Principal component analysis (PCA) showed a marked difference in the hepatic transcriptomic profiles of $P c c$-infected vs. heme-treated mice, compared to control fasted mice, respectively (Fig. S3A). Unsupervised hierarchical clustering segregated the differentially expressed transcripts (i.e. 9,623) into four clusters. These included transcripts induced preferentially upon Pcc infection (Cluster 1) or heme administration (Cluster 2), as well as transcripts repressed preferentially by 
PCC infection (Cluster 3) or heme administration (Cluster 4), as compared to control fasted mice, respectively (Fig. $3 A$ ).

There was approximately $40 \%$ overlap in the identity of the differentially expressed hepatic transcripts in mice infected by $P C C$ or receiving heme, as compared to control fasted mice, respectively (Fig. 3B; S3B). This was attributed to a $28.1 \%$ and $37.7 \%$ overlap in induced or repressed transcripts, respectively (Fig. 3B). Hmox1, encoding HO-1, was among the overlapping induced transcripts (Fig. S3B), while G6pc1 and Pck1, encoding phosphoenolpyruvate carboxykinase-cytosolic form (Pepck-C) (Fig. 3C; S3B) were among the overlapping repressed transcripts. Repression of the latter during Pcc infection was confirmed by qRT-PCR (Fig. 3D; See also Fig. 1D). This suggests that labile heme orchestrates a hepatic transcriptional response underlying the hypometabolic state imposed by Plasmodium infection.

\section{LABILE HEME MIMICS THE REPRESSION OF HGP DURING MALARIA (Fig. 3 \&S3)}

Functional enrichment analysis showed an overlap of the 12 metabolic pathways most significantly repressed in response to PCC or heme administration, as compared to control fasted mice, respectively (Fig. 3E; Table S1). These were involved in "regulation of small molecule metabolism", which includes gluconeogenesis, organic acid, oxoacid, carboxylic acid, monocarboxylic acid, lipid and amino acid metabolism (Fig. 3E). A broader analysis showed a $53 \%$ overlap of all pathways repressed in response to PCC infection or heme administration (Fig. S3C).

In contrast, the pathways most significantly induced in response to Pcc infection (i.e. immune and stress responses to biotic and/or organic substances) diverged from those induced upon heme administration (i.e. subcellular processes)(Fig. S3D, E; Table S2). When accounting for all pathways induced by PCC infection, only $23 \%$ were also induced in response to heme administration (Fig. S3F; Table S2).

The regulatory regions of the overlapping genes repressed during PCC infection and in response to heme administration, shared a number of GC-rich DNA-binding motifs recognized by the SP/KLF (Specificity protein/Kruppel-like factor) family of transcriptional regulators, including SP1, SP2, KLF3, KLF5, KLF7 and ZF5 (Fig. $S 3 G)$. The regulatory regions of these genes also shared DNA-binding motifs recognized by the E2F-1, E2F-3 and E2F-4 members of the E2F family of transcriptional regulators as well as by the zinc finger transcriptional regulators early growth response protein 1 (EGR1/KROX), CTCF or WT1 and by the Aryl hydrocarbon receptor $(\mathrm{AhR})($ Fig. S3G). A broader analysis showed an additional 
number of shared but also non-shared (Fig. S3G) DNA-binding motifs in the regulatory regions of $\sim 60 \%$ of these genes (Fig. S3H; Table S3).

In keeping with labile heme repressing G6pc1 transcription (Fig. 1D)(Yin et al., 2007), G6pc1 mRNA expression by primary mouse hepatocytes was repressed, in a dose-dependent manner, by exogenous heme, i.e. labile heme (Fig. 3F). To explore further how heme represses G6pc1 transcription, we used human HepG2 cells transiently transfected in vitro with luciferase reporters (Fig. 3G). Heme inhibited to the same extent (i.e. 31-36\%) the transcription of G6pc1-luciferase reporters regulated by the $-1380 /+60$ or the $-320 /+60$ base pair (bp) promoter region (i.e. from the TATA box), as compared to vehicle-treated control cells, respectively (Fig. 3G). In contrast, heme failed to repress the transcription of a minimal G6pc1-luciferase reporter controlled by the $-80 /+60$ bp promoter region (Fig. 3G). This suggests that labile heme represses G6pc1 transcription via a mechanism that targets one or several transcriptional regulators acting at the -320 to -80 bp region of G6pc1 promoter. This promoter region contains DNA-binding motifs recognized by SP1, SP2, KLF3, KLF5, EGR1 and Ahr but not by CTCF or WT1 (Fig. S3I), suggesting that labile heme represses hepatic G6pc1 transcription via a mechanism targeting one or several members of the SP/KLF family of transcription regulators and/or Ahr.

Glucocorticoids induce hepatic G6pc1 transcription via SP/KLF family of transcriptional regulators (Cui et al., 2019) and prevent the development of malariaassociated hypoglycemia (Vandermosten et al., 2018). Labile heme repressed the induction of G6pc1 and Pck1 mRNA in primary mouse hepatocytes exposed to the synthetic glucocorticoid dexamethasone (Fig. 3H), suggesting that labile heme impairs the protective effects of glucocorticoids against malaria-associated hypoglycemia.

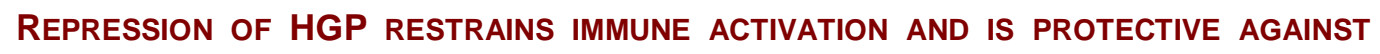
LIVER DAMAGE (Fig. 4, S4)

Immune activation relies to a large extent on glycolysis, required to fuel anabolic metabolism and leukocyte proliferation (Pearce et al., 2013). In support of the idea that regulation of HGP controls the immune response to Plasmodium infection, there was a marked reduction in the number of splenic natural killer (NK) and natural killer $\mathrm{T}$ (NKT) cells in Pcc-infected G6pc1 $1^{A l b \Delta / \Delta}$ vs. G6pc1 $1^{f / f l}$ mice (Fig. 4A,B). Splenic dendritic cell (Fig. $S 4 A, B$ ), monocyte (Fig. $S 4 A, C$ ) and red pulp macrophage (Fig. $S 4 A, D)$ numbers were similar, while the number of circulating neutrophils was higher in Pcc-infected G6pc1 $1^{A l b \Delta / \Delta}$ vs. G6pc1 $1^{f / f l}$ mice (Fig. S4E). 
The number of splenic T cells was also reduced in G6pc1 $1^{A l b \Delta / \Delta} v s$. G6pc1 ${ }^{f / f l}$ mice (Fig. 4A,B). This was associated with a reduction of splenic central memory $\left(\mathrm{CD} 4{ }^{+} \mathrm{CD} 44^{+} \mathrm{CD}^{2} \mathrm{~L}^{+}\right) \quad \mathrm{T}$ helper $\left(\mathrm{T}_{\mathrm{H}}\right)$ cells (Fig. 4C,D) but not naïve $\left(\mathrm{CD} 4{ }^{+} \mathrm{CD} 44^{\text {Low }} \mathrm{CD}^{2} \mathrm{~L}^{+}\right)$or effector memory $\left(\mathrm{CD} 4^{+} \mathrm{CD} 44^{+} \mathrm{CD} 62 \mathrm{~L}^{-}\right) \mathrm{T}_{\mathrm{H}}$ cells (Fig. 4C,D). The number of splenic central memory $\left(\mathrm{CD} 8^{+} \mathrm{CD} 44^{+} \mathrm{CD} 62 \mathrm{~L}^{+}\right)$cytotoxic $\mathrm{T}$ cells and naïve $\left(\mathrm{CD} 8^{+} \mathrm{CD} 44^{\text {low }}{ }^{\mathrm{CD}} 62 \mathrm{~L}^{+}\right)$cytotoxic $\mathrm{T}$ cells was also reduced in PCC infected G6pc1 $1^{A l b \Delta / \Delta}$ vs. G6pc1 $1^{f / f t l}$ mice (Fig. 4E,F). This was not the case for effector memory $\left(\mathrm{CD}^{+} \mathrm{CD} 44^{+} \mathrm{CD} 62 \mathrm{~L}^{-}\right)$cytotoxic $\mathrm{T}$ cells (Fig. 4E,F). Taken together, these data suggest that repression of HGP restrains the activation and/or expansion of central memory $T_{H}$ and cytotoxic $T$ cells in response to Plasmodium infection.

$P c c$-infected $G 6 p c 1^{A l b \Delta / \Delta}$ mice also showed a marked reduction in granulocytecolony stimulating factor (G-CSF) and interferon gamma (IFN $\gamma$ ) concentration in plasma, compared to G6pc $1^{f / f l}$ mice (Fig. 4G). Other cytokines and chemokines were not affected, except for eotaxin (Fig. S4F) and TNF, but the later did not reach statistical significance (Fig. 4G).

Repression of HGP in Pcc-infected G6pc1 $1^{A l b \Delta / \Delta}$ mice was associated with protection from liver damage, compared to $G 6 p c 1^{\text {fl/fl }}$ mice. This was revealed by a lower accumulation of alanine transaminase (ALT) in plasma (Fig. $4 H$ ) and confirmed by histological analyzes (Fig. 4I).

\section{RePRESSION Of HGP REgULATES PLASMOdIUM BeHAVIOR (Fig. 5\&S5)}

P. falciparum development and proliferation in vitro are dependent on glucose (Hirako et al., 2018; MacRae et al., 2013; Olszewski and Llinas, 2011; Salcedo-Sora et al., 2014; Srivastava et al., 2016), suggesting that repression of HGP might impact on Plasmodium spp. development and/or proliferation in vivo. In support of this hypothesis, the number of circulating RBC was higher throughout the course of PCC infection in G6pc1 $1^{A l b \Delta / \Delta}$ vs. G6pc1 $1^{f / f l}$ mice (Fig. 5A,B; S5A). In contrast, the maximal percentage of circulating iRBC was lower in $G 6 p c 1^{A l b \Delta / \Delta}$ vs. G6pc1 fl/fl mice, "normalizing" the pathogen burden among genotypes (Fig. 5A,B).

That repression of HGP limits the severity of anemia imposed by Plasmodium infection was corroborated by an increase of $\mathrm{Hb}$ concentration, hematocrit and mean corpuscular hemoglobin concentration (MCHC), as well as a decrease in RBC mean corpuscular volume (MCV) in Pcc-infected G6pc1 $1^{A l b \Delta / \Delta}$ vs. G6pc1 ${ }^{f / f l}$ mice (Fig. S5A). $\mathrm{RBC}$ mean corpuscular hemoglobin $(\mathrm{MCH})$ and distribution RBC width (RDW) were also closer to the physiological range in Pcc-infected G6pc1 $1^{A l b \Delta / \Delta}$ compared to G6pc1 ${ }^{f / f l}$ mice (Fig. S5A). 
Additionally, Pcc-infected $G 6 p c 1^{A l b \Delta / \Delta}$ also had a marked decrease in erythropoietin concentration in plasma, compared to G6pc1/f/fl mice (Fig. 5C). Given that erythropoietin is the main hormone responsible for the induction of erythropoiesis in response to anemia, this observation supports further the idea that repression of HGP is protective against the anemia caused by Plasmodium infection.

We hypothesized that repression of HGP restrains anemia via a mechanism that acts on Plasmodium. To test this hypothesis we performed single-cell RNAsequencing (scRNAseq) in (GFP ${ }^{+}$) iRBC FACS-sorted from G6pc1 $1^{A l b \Delta / \Delta}$ and G6pc1 $1^{f / / t}$ mice. Parasite transcriptomes were segregated into nine clusters (Fig. 5D,E), ascribed to different developmental stages, according to the 25 most highly expressed transcripts and by comparison to $P$. falciparum and $P$. berghei gene orthologues (Table S4). Clusters 0, 2 and 7 (Table S4) corresponded to early ring stages (Fig. 5E; S5B) and clusters 1 and 4 to trophozoites (Fig. 5E; S5B). Cluster 3 included transcripts associated with ring stages, trophozoites and early schizont stages (Table S4), but also with Plasmodium sexual commitment, suggesting that cluster 3 includes early stages of gametocyte development (Fig. 5E; S5B). Clusters 5 and 6 (Table S4) corresponded to schizonts, while cluster 6 was associated with early schizonts (Fig. 5E; S5B). Cluster 8 corresponded to gametocytes (Table S4; Fig. 5E; S5B).

The number of parasite transcriptomes per iRBC from G6pc1 $1^{A l b \Delta / \Delta}$ mice was 3fold higher, compared to G6pc1/ffll mice (Fig. 5E,F). This was not related to the number of iRBC $\left(\mathrm{GFP}^{+}\right)$processed (Fig. S5C). The frequency of transcriptomes corresponding to each Plasmodium cluster was also different in iRBC from G6pc1 $1^{A l b \Delta / \Delta}$ vs. G6pc1 $1^{f / f l}$ mice (Fig. 5E,F). There was a relative increase in the number of transcriptomes corresponding to ring stages and trophozoites (i.e. clusters $0-2,4,7,3)$ and a reduction in transcriptomes corresponding to schizonts (i.e. clusters 5,6$)$. Moreover, there was an additional parasite transcriptome cluster in iRBC from G6pc1 $1^{A l b \Delta / \Delta}$ mice, corresponding to gametocytes (i.e. cluster 8), which as barely detected in iRBC from G6pc $1^{f / f t}$ mice (Fig. 5E,F). This suggests that parasites from G6pc1 $1^{A l b \Delta / \Delta}$ mice undergo gametocytogenesis (Yuda et al., 2015). Of note, transcripts corresponding to the parasite glycolytic enzymes were detected preferentially in clusters $1,4,5,6$, and 8 , corresponding to trophozoites, schizonts and gametocytes, respectively. In contrast, transcripts corresponding to TCA-related enzymes were detected mainly in cluster 8 , corresponding to gametocytes, and to a lower extent in clusters 1 and 6 (Table S5). 
RNA velocity analysis of temporal transcriptome transitions (Bergen et al., 2020) suggested that parasites in $G 6 p c 1^{t / / f l}$ mice followed the expected developmental progression through schizonts (i.e. cluster 5/6) towards ring stages and trophozoites (i.e. clusters $0,1,2,4,7$ ), with minimal sexual commitment (i.e. cluster 3,8 ). This was severely altered in parasites from G6pc1 $1^{A l b \Delta / \Delta}$ mice, in that schizonts (i.e. cluster 6) appear to undergo sexual commitment (i.e. cluster 3 ), as revealed by the expression of transcriptomes corresponding to gametocytes (i.e. cluster 8) (Fig. 5G). Moreover, there was an apparent "backward transition" from trophozoites (i.e. clusters $0,1,2,4$ ) and schizonts (i.e. cluster 5) towards rings (i.e. cluster 7) as well as an arrest of schizont transition from cluster 5 to cluster 6 (Fig. 5G). This suggests that repression of HGP is associated with a developmental arrest of asexual stages of Plasmodium, while favoring sexual commitment. Of note, there was a marked repression of transcripts involved in DNA replication and transcriptional regulation (Fig. 5H, Table S6), while transcripts related to translation, but also heat-shock proteins, were induced in parasites from G6pc1 $1^{A l b \Delta / \Delta}$ vs. G6pc1 $1^{f / f l l}$ mice (Fig. 5H, Table S6). Functional enrichment analysis confirmed the repression of DNA replication (Fig. S5D) and anabolic metabolism (Fig. S5E, F).

RePREssion Of HGP ReduCES Plasmodium ViRULenCe (Fig. 5\&6).

Parasites from $G 6 p c 1^{A l b \Delta / \Delta}$ mice reduced the expression of transcripts corresponding to virulence factors (Fig. 5H, Table S6), as confirmed for hmgb2 (Briquet et al., 2015) and famb (Brugat et al., 2017), by qRT-PCR (Fig. 6A). Infection of G6pc1 $1^{A l b \Delta / \Delta}$ mice with parasites isolated from $G 6 p c 1^{A l b \Delta / \Delta}$ mice, led to lower incidence of mortality, compared to infection with parasites from G6pc1/f/ll mice (Fig. 6B). This was associated with reduced temperature-loss (Fig. S6A), without changes in pathogen load (Fig. 6B) or glycemia (Fig. S6B). This data shows that repression of HGP reduces $P C c$ virulence.

\section{REPRESSION OF HGP INDUCES PLASMODIUM PYKNOSIS (Fig. 6\&S6)}

The number of circulating iRBC containing pyknotic parasites was increased by 7.6fold at the peak of Pcc infection in G6pc1 $1^{A l b \Delta / \Delta} v s$. G6pc1 $1^{f / f l}$ mice, as assessed morphologically in Giemsa-stained blood smears (Fig. 6C; S6C,D). This increase in pyknotic parasites occurred at the lowest levels of glycemia (Fig. S6D), suggesting that lowering glycemia, via the repression of HGP, induces Plasmodium pyknosis in vivo. 
We than asked whether lowering glucose concentration is sufficient per se to induce parasite pyknosis. The percentage of human RBC infected in vitro by $P$. falciparum (i.e. parasitemia; \% iRBC) was reduced in a dose dependent manner when glucose concentrations lower than $6 \mathrm{mmol} / \mathrm{L}$ (i.e. $110 \mathrm{mg} / \mathrm{dL})($ Fig. $6 E ;$ S6E). This was directly correlated with accumulation of pyknotic parasites (Fig. 6F, Fig. $S 6 E-G)$ and by reduction of parasite mitochondrial function, revealed by loss of membrane potential $(\Delta \Psi \mathrm{m})($ Fig. $6 \mathrm{G}, \mathrm{H}$, Fig. S6H). This suggests that repression of HGP arrests the development of asexual stages of Plasmodium spp. when blood glucose concentration falls below the $6 \mathrm{mmol} / \mathrm{L}$ (i.e. $110 \mathrm{mg} / \mathrm{dL}$ ) threshold.

\section{Repression Of HGP InduCES PLASMOdIUM SEXUAL DifFERENTIATION (Fig. 6\&S6)}

The number of circulating iRBC containing gametocytes was increased by 8.6-fold at the peak of Pcc infection in G6pc1 $1^{A l b \Delta / \Delta}$ vs. G6pc1 $1^{f / / f l}$ mice, as assessed by Giemsastaining (Fig. 6I, S6C-D). This was corroborated by the accumulation of mRNA encoding gametocyte-specific genes, as assessed for g377, gest and gep1 by qRTPCR (Fig. 6J), confirming that repression of HGP induces gametocytogenesis and production of circulating gametocytes

\section{HGP SUSTAINS THERMOREGULATION IRRESPECTIVELY OF BAT THERMOGENESIS (Fig. 7 )}

We asked whether repression of HGP controls the thermoregulatory response to PCC infection via a mechanism involving brown adipose tissue (BAT) thermogenesis (Enerbäck et al., 1997). Pcc infection was associated with repression of BAT thermogenesis, to a similar extent in $G 6 p c 1^{A l b \Delta / \Delta}$ and $G 6 p c 1^{f / f t}$ mice (Fig. 7A,B). However, this was not associated with a corresponding decrease of tail temperature in PcC-infected G6pc1 $1^{A l b \Delta / \Delta}$ mice (Fig. 7B), suggesting that heat dissipation (i.e. difference between tail and core body temperature) was higher in Pcc-infected G6pc1 $1^{A l b \Delta / \Delta}$ vs. G6pc $1^{f / f l}$ mice (Fig. 7C).

We than tested whether the thermoregulatory response to Pcc infection relies on the capacity of BAT to transform chemical energy into heat through a mechanism involving the mitochondrial uncoupling protein 1 (UCP1)(Enerbäck et al., 1997). Ucp1 deletion $\left(U_{c p} 1^{-/}\right)$did not affect the thermoregulatory response to Pcc infection (Fig. 7D) and had no impact on the survival (Fig. 7E) or pathogen load (Fig. 7F) in PCCinfected $U c p 1^{1-}$ vs. Ucp ${ }^{+/+}$mice. However, reduction of glycemia was less pronounced in Pcc-infected Ucp $1^{1 /}$ vs. Ucp $1^{+/+}$mice (Fig. 7G). This suggests that, in contrast to the thermoregulatory response to cold stress (Enerbäck et al., 1997) or to bacterial infection (Ganeshan et al., 2019), BAT thermogenesis is not essential to 
sustain core body temperature, while contributing to reduce glycemia during Pcc infection.

Host Glycemia and Core body temperature Regulate Plasmodium BehaVIor IN VIVO (Fig. 7\&S7)

To investigate further the mechanism via which glycemia regulates Plasmodium behavior, C57BL/6 mice were rendered hyperglycemic (i.e., glucose $>400 \mathrm{mg} / \mathrm{dL}$ ) using streptozocin (STZ) (Fig. S7A). Glycemia was reduced in response to PCC infection, to the same levels in STZ-treated vs. control mice (Fig. S7A). Moreover, hyperglycemia was restored upon PCC clearance in STZ-treated mice (Fig. S7A), suggesting that insulin production by $\beta$-cells of the pancreas (i.e. destroyed by STZ) does not regulate glycemia in response to Plasmodium infection.

Hyperglycemic mice developed higher pathogen loads, compared to control mice (Fig. S7B,C). This was not associated with increased mortality (Fig. S7D) nor with changes in core body temperature (Fig. S7E), body-weight (Fig. S7F) or severity of anemia (Fig. S7G). This strengthens the idea that reducing glycemia, via repression of HGP, restrains the development of Plasmodium asexual stages.

To dissect the relative impact of glycemia vs. core body temperature on Plasmodium behavior, we considered that mice are not at thermoneutrality when maintained at standard husbandry conditions $\left(22^{\circ} \mathrm{C}\right)$, allocating a significant proportion of EE to sustain core body temperature (Ganeshan and Chawla, 2017). At thermoneutral conditions $\left(31-32^{\circ} \mathrm{C}\right), P c c$ infected C57BL/6 mice reduced core body temperature to a lesser extent, compared to controls maintained at standard $\left(22^{\circ} \mathrm{C}\right)$ conditions (Fig. $7 H$ ). This was associated with an increase in pathogen load (Fig. $7 \mathrm{I}, \mathcal{J})$ but not with increased mortality (Fig. S7H). Moreover, under thermoneutral conditions PCC-infected mice did not reduce glycemia (Fig. S7I) or body weight (Fig. $S 7 J)$ to the same extent as mice maintained under standard conditions and exhibited less severe anemia (Fig. S7K). This shows that re-allocation of EE from thermoregulation towards anabolic processes sustaining glycemia, RBC numbers and body weight occur at the cost of increased pathogen load. This suggests therefore that Plasmodium senses and reacts to the host's core body temperature.

To examine the relative impact of glycemia and host core body temperature on the development of asexual stages of Plasmodium, the outcome of Pcc infection was compared in $G 6 p c 1^{A l b \Delta / \Delta}$ mice maintained at thermoneutral vs. standard conditions. At thermoneutrality, $P c c$-infected $G 6 p c 1^{A l b \Delta / \Delta}$ mice decreased core body temperature to a lesser extent than $G 6 p c 1^{A l b \Delta / \Delta}$ mice housed at standard temperature (Fig. $7 K$ ). This was associated with an increase in pathogen load (Fig. $7 L, M$ ) and a borderline 
increase in mortality (Fig. S7L). Of note, PCc-infected G6pc1 $1^{A l b \Delta / \Delta}$ mice had similar glycemia (Fig. S7M), body weight loss (Fig. S7M) and severity of anemia (Fig. S7O) at thermoneutral vs. standard conditions. These observations suggest that repression of HGP induces a hypometabolic state whereby lowering body temperature contributes critically to modulate Plasmodium behavior.

\section{Discussion}

PCC infection in C57BL/6 mice is associated with the development of anorexia (Fig. $1 A, B$ ) and the reduction of blood glucose concentration (Fig. 1C)(Cumnock et al., 2018; Elased and Playfair, 1994). The latter relies on the repression of hepatic G6pc1 expression (Fig. 1D,E) and HGP (Fig. 1F), which is restored over time to prevent the development of hypoglycemia (Fig. 1I-L) from compromising the energetic demands of the infected host (Fig. $2 A-H)$. While perceived as a pathologic event per se, this hypometabolic state represents an evolutionary trade-off (Stearns and Medzhitov, 2015) of an otherwise adaptive response to Plasmodium spp. infection, whereby host and pathogens compete to access vital metabolites and micronutrients, such as iron and glucose, in detriment of each other.

Asexual stages of Plasmodium spp. can consume up to an estimated $60-80 \%$ of $\mathrm{RBC} \mathrm{Hb}$ content, detoxifying excess heme and its associated iron in the form of hemozoin crystals (Sigala and Goldberg, 2014). The remaining $\mathrm{Hb}$ content is released upon hemolysis (Francis et al., 1997) as $\mathrm{Hb}(\alpha 2 \beta 2)$ tetramers, which disassemble into $(\alpha \beta)$ dimers in plasma, releasing non-covalently bound heme (Hebbel et al., 1988; Pamplona et al., 2007) and producing labile heme (Ademolue et al., 2017; Elphinstone et al., 2016; Gouveia et al., 2017). As it accumulates in plasma, labile heme acts as an alarmin (Soares and Bozza, 2016), sensed by host pattern recognition receptors (Dutra and Bozza, 2014) and promoting the pathogenesis of severe forms of malaria (Knackstedt et al., 2019; Pamplona et al., 2007). When it accumulates in plasma at relatively low levels however, labile heme can elicit a protective response against severe malaria, such as the one underlying the beneficial effect of sickle $\mathrm{Hb}$ against malaria (Ferreira et al., 2008). Our current findings are consistent with this dual (i.e. pathologic vs. protective) effect of labile heme, whereby labile heme induces a hypometabolic state that restricts the development of asexual stages of Plasmodium while promoting malaria-associated hypoglycemia. In support of this idea, labile heme is sufficient to recapitulate the hallmarks of this hypometabolic state in non-infected mice, inducing a transient state 
of anorexia (Fig. $1 B$ and $2 l, J$ ), repressing HGP (Fig. 1D-F and $3 F-H$ ), reducing glycemia (Fig. 1C)(Weis et al., 2017) and decreasing EE (Fig. 2M,N).

Labile heme induces this hypometabolic state via a mechanism that relies on the transcriptional repression of hepatic metabolic genes, including G6pc1 (Fig. 3C-H). This occurs, most likely, via the inhibition one or several members of the SP/KLF family of transcription regulators (Fig. S3G-I), including SP1, which sustains G6pc1 transcription (Wasner et al., 2001). SP1 can bind to the heme sensor Reverb $\alpha$ (Negoro et al., 2013), a transcriptional repressor (Raghuram et al., 2007) that inhibits G6pc1 transcription (Yin et al., 2007). We speculate that upon heme sensing, Rev-erb $\alpha / \beta$ binds to SP1 and/or other SP/KLF family in the G6pc1 promoter (Zhang et al., 2015), repressing G6pc1 transcription and HGP.

Repression of HGP in response to Pcc infection is protective against liver damage (Fig. 4H,I), a hallmark of severe malaria (Knackstedt et al., 2019; Miller et al., 2002). The mechanism via which this occurs is most likely linked to a reduction in splenic NK and NKT cells and IFN- $\gamma$ production (Fig. 4A-G). This is consistent with IFN- $\gamma$ production by activated NK cells relying on glycolysis (Donnelly et al., 2014) and promoting organ damage during severe malaria (Franklin et al., 2009; Su and Stevenson, 2000).

This immunosuppressive effect did allow Pcc immune evasion (Fig. $1 K, L$ ) and was associated instead with marked repression of the development of asexual stages of Pcc (Fig. 5A,B). This suggests that the hypometabolic state imposed by labile heme, via the repression of HGP and the reduction of glycemia, is a component of innate nutritional immunity (Nunez et al., 2018). Presumably, this defense strategy restrains asexual stages of Plasmodium spp. from accessing not only glucose, but perhaps other essential host-derived metabolites and micronutrients, such as amino acids (e.g. isoleucine or glutamine) or lipids (i.e. lysophosphatidylcholine)(Kumar et al., 2021; Mancio-Silva et al., 2017). This interpretation is consistent with glycolysis being required to support the high energetic demands and anabolic metabolism inherent to the proliferation of asexual stages of $P$. falciparum (Homewood, 1977; Meireles et al., 2017; Olszewski and Llinas, 2011). Moreover, glycolysis is also essential to fuel $P$. falciparum pentose phosphate pathway and maintain parasite redox balance and viability (Preuss et al., 2012a).

Repression of HGP is sensed, directly or indirectly, by asexual stages of Plasmodium and reacted upon via a transcriptional response associated with the induction of parasite pyknosis (Fig. 6C,D, S6C,D). This is paralleled by the induction of sexual differentiation, characterized by the generation of high numbers of 
circulating gametocytes (Fig. 5E-G, 6I, J), a reliable predictor of malaria transmission (Mackinnon and Read, 1999). This suggests that repression of HGP and hypoglycemia favor malaria transmission.

The observation that repression of HGP induces Plasmodium sexual commitment, presumably to favor malaria transmission (Fig. 5E-G, 6l,J), while reducing virulence (Fig. $5 H, 6 A, B$ ) is reminiscent of that observed during bacterial infection, whereby iron reprograms host glucose metabolism to regulate bacterial transmission vs. virulence (Rao et al., 2017; Weis et al., 2017). This suggests that cross-regulation of host iron and glucose metabolism, is an evolutionarily conserved defense strategy against infection by different classes of pathogens.

Our interpretation is that reprogramming of host iron-heme metabolism in response to infection induces a coordinated response, whereby anorexia is coupled to the repression of HGP to reduce glycemia and deprive asexual stages of Plasmodium from accessing glucose, impairing parasite development and inducing parasite pyknosis (Fig. 6C-F, S6C-G). This defense strategy carries two major tradeoffs, namely the development of malaria-associated hypoglycemia, an independent risk factor of malaria mortality (Madrid et al., 2015; Marsh et al., 1995; Service, 1995; White et al., 1983) and a possible increase in parasite transmission.

HGP regulates the thermoregulatory response to malaria (Fig. $7 A-C$ ), possibly interfering with the development of asexual stages of Plasmodium spp. (Fig. $7 \mathrm{H}$ $M$ (Rojas and Wasserman, 1993). In contrast to humans, which increase body temperature, i.e. fever, as a cardinal sign of Plasmodium spp. infection (Evans et al., 2015), mice appear to suppress HGP and reduce core body temperature as an alternative strategy to restrain the development and proliferation of asexual stages of Plasmodium (Fig. $7 \mathrm{H}-\mathrm{M}$ ), in keeping with thermoregulation being an evolutionarily conserved defense strategy against infection (Schieber and Ayres, 2016).

In contrast to the canonical thermoregulatory response to cold stress (Enerbäck et al., 1997) or to systemic bacterial infection (Ganeshan et al., 2019), the thermoregulatory response to PCC infection does not rely on UCP1-dependent BAT thermogenesis (Fig. 7A-G). It occurs instead via a mechanism whereby repression of HGP limits glucose supply to support heat generation inherent to organismal metabolism (Fig. 2A,B) while sustaining heat dissipation (Fig. 7A-C). This strategy carries a major risk of core body temperature falling below a threshold compatible with host survival. This is likely aggravated by voracious glucose consumption by asexual stages of Plasmodium (Olszewski and Llinas, 2011; Thien et al., 2006) as 
well as by proliferating immune cells (Buck et al., 2017; Man et al., 2017; Wang et al., 2019).

In conclusion, labile heme orchestrates a host hypometabolic response that restricts asexual stages of Plasmodium from accessing glucose, a vital nutrient supporting parasite development and proliferation. When sustained over time this host defense strategy becomes a driving force in the pathogenesis of malariaassociated hypoglycemia. Asexual stages of Plasmodium can sense the development of hypoglycemia either directly, or indirectly via the associated decrease of core body temperature, activating a transcriptional program that reduces virulence and promotes sexual differentiation, presumably as a strategy favoring malaria transmission.

ACKNOWLEDGEMENTS We are indebted to Dr. Silvia Portugal (Max Plank Institute, Berlin) and Dr. Jessica Ann Thompson (Instituto Gulbenkian de Ciência) for critical review of the manuscript, Dr. Joanne Thompson (University of Edinburgh) for the PcAS-GFP ${ }_{M L}$ parasites; BEI Resources for P. falciparum parasites (MRA-1029, deposited by Andrew M. Talman and Robert E. Sinden), excellent support from IGC's Advanced Imaging; Antibody; Flow Cytometry and Genomics facilities. SR was supported by Fundação para a Ciência e Tecnologia (FCT; 5723/2014; FEDER029411), TWA by Gulbenkian foundation (IBB2017), EJ by the Deutsche Forschungsgemeinschaft (DFG, EXC 2051; 390713860), ARC by FCT (SFRH/BPD/101608/2014), SW and JG by the by the Center for Sepsis Control and Care (CSCC), Jena University Hospital (BMBF 01EO1502) and DFG (EXC 2051; 390713860 and WE 4971/6-1), DD and FN were supported by FCT through GHTM (UID/04413/2020). The MPS laboratory at Instituto Gulbenkian de Ciência is supported by the Gulbenkian Foundation and by "La Caixa" (HR18-00502) and FCT (5723/2014; FEDER029411) foundations. MPS is an associate member of the DFG Cluster of Excellence 'Balance of the Microverse' (https://microverse-cluster.de/en). Support by Congento (LISBOA-01-0145-FEDER-022170) is acknowledged.

\section{AUTHOR CONTRIBUTION}

SR and TWA contributed critically to study design, experimental work, data analyzes and interpretation. EJ designed (with TWA), performed Plasmodium scRNA and analyzed data (with SR, AS and JL). QW carried in vitro experiments on heme regulation of gluconeogenesis, following initial experiments by ARC. JG and SW performed indirect calorimetry measurements of heme-treated mice and analyzed 
data. RM designed and performed flow cytometry experiments (with TWA). GP assisted SR and TWA in experiments related to Plasmodium virulence. IM and ES assisted SR and TWA in experiments related to the induction of anorexia in response to Plasmodium infection. SC maintained and characterized mouse strains. TWA performed bulk-RNA sequencing experiments and contributed to analyzes by AS and JL. GM and FR participated in data interpretation. FN designed, performed and analyzed $P$. falciparum glucose tolerance in vitro experiments (with SR). DD assisted FN in in vitro experiments. MPS formulated the original hypothesis, designed the study and wrote the manuscript with SR and TWA. All authors read and approved the manuscript.

\section{DECLARATION OF INTEREST}

The authors declare no competing interests.

\section{MAIN FIGURE LEGENDS}

\section{Figure 1. HGP controls glycemia during Pcc infection (see also Figure S1)}

(A) Parasitemia (\% iRBC) and number of RBC per $\mu \mathrm{L}$ of blood in Pcc-infected $\mathrm{C} 57 \mathrm{BL} / 6$ mice $(\mathrm{N}=6)$. Data represented as mean $\pm \mathrm{SD}$, pooled from two independent experiments with similar trend.

(B) Daily food intake (mean $\pm \mathrm{SD}$ ) in Pcc-infected C57BL/6 mice $(\mathrm{N}=6)$. Data pooled from two independent experiments with similar trend.

(C) Glycemia (mean $\pm S D$ ) in same mice as (A).

(D) Hepatic G6pc1 mRNA (normalized to Arbp0; mean \pm SD) from Pcc-infected C57BL6 mice ( $\mathrm{N}=5-10$ per day), quantified by qRT-PCR. Data pooled from 2 independent experiments with similar trend.

(E) G6pc1 protein (normalized to Gapdh; mean \pm SD) in same mice as (D), quantified by western blot (lower panel).

(F) Percent variation $(\Delta)$ of glycemia (right panel) after pyruvate administration (PTT) to C57BL6 mice, naïve (Control; Ctr.; $\mathrm{N}=4$ ) or at the peak of Pcc infection ( $\mathrm{N}=4)$. Area under the curve (AUC; right panel) corresponding to PTT. Data from one experiment shown as mean $\pm \mathrm{SD}$.

(G) Glycemia (right panel) after glucose administration (GTT) to C57BL6 mice, naïve (Control; Ctr.; $\mathrm{N}=5$ ) or at the peak of Pcc infection ( $\mathrm{N}=4$ ). Area under the curve (AUC; right panel) corresponding to GTT. Data from one experiment shown as mean \pm SD. 
(H) Glucose concentration (right panel) after insulin administration (ITT) to C57BL6 mice, naïve (Control; Ctr.; $\mathrm{N}=5)$ or at the peak of Pcc infection $(\mathrm{N}=4)$. Area under the curve (AUC; right panel) corresponding to ITT. Data from one experiment shown as mean $\pm \mathrm{SD}$.

(I) Individual disease trajectories of $G 6 p c 1^{A l b \Delta / \Delta}\left(\mathrm{N}=15\right.$; purple lines) and $G 6 p C 1^{f / / f l}$ ( $\mathrm{N}=12$; gray lines) mice, established by the relationship of blood glucose concentration and parasite density throughout a 15 day course of Pcc infection. Data pooled from 3 independent experiments with similar trend. Circles indicate death of individual mice.

(J) Minimum blood glucose concentration (mean \pm SEM), throughout the 15-day course of Pcc infection in the same mice as (I).

(K) Survival after Pcc infection, in the same mice as (I).

(L) Pathogen load (i.e. number of iRBC per $\mu \mathrm{L}$ of blood; mean \pm SEM) in the same mice as (I).

$P$ values calculated by Mann-Whitney $U$ test in $(B, C, J)$, One-Way ANOVA with Holm-Sidak's multiple comparison test in (D, E), Two-Way ANOVA with Tukey's multiple comparison test in $(F-H, L), t$ test for $A U C$ in $(F-H)$ and Log-rank (MantelCox) test (conservative) in (K). ns: non-significant; * $P<0.05$; ${ }^{* *} P<0.01$; ${ }^{* * *} P<0.001$; ${ }^{* * * *} P<0.0001$.

Figure 2. HGP regulates EE during Plasmodium infection (see also Figure S2)

(A-H) Synchronized metabolic and behavioral quantification of $G 6 p c 1^{A l b \Delta / \Delta}(\mathrm{N}=4$; purple circles) and $G 6 p C 1^{f / l f l}$ ( $\mathrm{N}=4$; white circles) mice, from 6 to 9 days after PcC infection. Data from one experiment.

(A) Hourly energy expenditure (EE), represented as mean \pm SEM.

(B) Mean of hourly EE ( \pm SEM), corresponding to the light blue period in (A). Data segregated into daily light/dark cycle.

(C) Mean daily food intake corresponding to the period indicated by light blue in (A) \pm SEM, segregated into daily light/dark cycle.

(D) Mean of total activity (1-hour binning values per mouse) corresponding to the period indicated by light blue in (A), \pm SEM, segregated into daily light/dark cycle.

(E) Hourly respiratory exchange ratio $(R E R)$ represented as mean \pm SEM. 
(F) Mean of hourly RER corresponding to the period indicated by light blue in $(E) \pm$ SEM, segregated into daily light/dark cycle.

(G) Mean of hourly volume of exhaled $\mathrm{CO}_{2}$ corresponding to the period indicated by light blue in $(E) \pm S E M$, segregated into daily light/dark cycle.

$(\mathrm{H})$ Mean of hourly volume of inhaled $\mathrm{O}_{2}$ corresponding to the period indicated by light blue in $(E) \pm S E M$, segregated into daily light/dark cycle.

(I-P) Synchronized quantification of metabolic and behavioral parameters in C57BL/6 mice receiving heme $(30 \mathrm{mg} / \mathrm{Kg} ; \mathrm{N}=4$; brown circles) or control protoporphyrin IX (PPIX; $\mathrm{N}=4$; white circles), at the times indicated by an arrow. Data from two experiment representative of three independent experiments with similar trend.

(I) Mean daily food-intake \pm SEM.

(J) Mean food-intake corresponding to the $24 \mathrm{~h}$ period highlighted in light blue in (I) \pm SEM, segregated into daily light/dark cycle.

(K) Total activity represented as mean \pm SEM.

(L) Mean total activity, corresponding to the $24 \mathrm{~h}$ period highlighted in light blue in (I) \pm SEM, segregated into daily light/dark cycle.

(M) Energy expenditure (EE) represented as mean \pm SEM.

(N) Mean EE, corresponding to the $24 \mathrm{~h}$ period highlighted in light blue in (I) \pm SEM, segregated into daily light/dark cycle.

(O) Hourly respiratory exchange ratio (RER), represented as mean \pm SEM.

(P) Mean EE, corresponding to the $24 \mathrm{~h}$ period highlighted in light blue in (I) \pm SEM, segregated into daily light/dark cycle.

$P$ values in all panels were determined using Two-Way ANOVA with Sidak's multiple comparison test. $n s-$ non-significant; ${ }^{* *}-p<0.01 ;^{* * *}-p<0.001 ;{ }^{* * *}-p<0.0001$.

Figure 3. Labile heme recapitulates the repression of HGP in response to Plasmodium infection. (see also Figure S3)

(A-C) Bulk RNA-seq analyzes from the liver of C57BL/6 mice subjected to fasting (Overnight; $15 \mathrm{~h} ; \mathrm{N}=4)$, receiving heme $(30 \mathrm{mg} / \mathrm{Kg}$, Overnight; $\mathrm{N}=3)$ or infected with $P C C$ (at the peak of infection; $\mathrm{N}=4$ ) 
(A) Heatmap of unsupervised clustering analysis of 18,163 differentially expressed Zscore log transformed transcripts. Purple: Transcripts with common pattern of expression in mice receiving heme and infected with Pcc, compared to fasted control mice, respectively. Green: Transcripts with unique expression pattern in mice receiving heme. Yellow: Transcripts with an expression pattern unique to Pcc infected mice.

(B) Venn diagrams of transcripts differentially expressed (top panel), transcripts upregulated (middle panel) or transcripts down regulated (bottom panel), in mice receiving heme or $P c c$-infected mice, compared with control fasted mice, respectively.

(C) Normalized G6pc1 and Pck1 read counts from RNA-seq in (A).

(D) Hepatic Pck1 mRNA expression (mean \pm SD), in Pcc-infected C57BL6 mice ( $\mathrm{N}=5-10$ per day), quantified by qRT-PCR and normalized to Arbp0. Data pooled from 2 independent experiments with similar trend.

(E) Functional enrichment analysis, using GO terms database, of transcripts down regulated in mice receiving heme and $P c c$-infected mice. Only pathways with the highest enrichment score (- $\log 10$ adjusted p-value) are represented. (aa: amino acid).

(F) G6pc1 (left panel) and Pck1 (right panel) mRNA expression (mean \pm SD) in primary mouse hepatocytes exposed in vitro to heme (12h), quantified by qRT-PCR and normalized to Arbp0. Data from one out of 3 independent experiments with similar trend.

(G) Relative luciferase units (RLU) in HepG2 cells transiently co-transfected in vitro with firefly luciferase reporters, regulated by the full length $(-1380)$ or truncated $(-320$ and -80) G6pc1 promoters and a Renilla luciferase reporter regulated by a minimal CMV promoter. Firefly RLU were normalized to Renilla Luciferase activity and data is represented as fold induction, compared to HepG2 cells transiently transfected with an empty firefly luciferase reporter (pGL2B), (i.e. baseline; $1 \mathrm{RLU}$ ). HepG2 cells were exposed to heme $(40 \mu \mathrm{M}) 48 \mathrm{~h}$ after transfection and analyzed $12 \mathrm{~h}$ thereafter. Data represented as mean $\pm S D$, pooled from 2 independent experiments with similar trend.

(H) G6pc1 (left panel) Pck1 (right panel) mRNA expression (mean \pm SD) in primary mouse hepatocytes exposed to Dexamethasone (Dex; $100 \mathrm{nM})$, heme $(10 \mu \mathrm{M})$ or 
Dexamethasone plus heme (12h), quantified by qRT-PCR and normalized to Arbpo. Data pooled from 2 independent experiments with similar trend.

$P$ values in $(\mathrm{C}, \mathrm{D}, \mathrm{F}-\mathrm{H})$ determined using One-Way ANOVA with Sidak's multiple comparison test. Hypergeometric p-values in (E) were computed after correction for multiple testing. $n s-$ non-significant; ${ }^{*} p<0.05 ;{ }^{* *} p<0.01 ;{ }^{* * *} p<0.001 ;{ }^{* * *} p<0.0001$.

Figure 4. Repression of HGP restrains immune-driven inflammation and liver damage in response to Pcc infection. (see also Figure S4)

(A, B) Splenic NK (NK1.1 $\left.{ }^{+} \mathrm{CD} 3^{-}\right)$, NKT $\left(\mathrm{NK} 1.1^{+} \mathrm{CD}^{+}\right)$and $\mathrm{T}\left(\mathrm{NK} 1.1^{-} \mathrm{CD}^{+}\right)$cells in G6pc1 ${ }^{A l b \Delta / \Delta}$ (purple dots) and G6pC1 $1^{\text {fl/fil }}$ (white dots) mice not infected (NI; N=4 per genotype) and at the peak of $P c c$-infection ( $\mathrm{N}=6$ per genotype). Data pooled from 2 independent experiments with similar trend.

(A) Representative FACS plots.

(B) Quantification of $(A)$ represented as mean (red bar) $\pm S D$, from individual mice represented by circles.

(C, D) Splenic naïve $\left(\mathrm{CD} 4{ }^{+} \mathrm{CD} 44^{\text {low }} \mathrm{CD} 2 \mathrm{~L}^{+}\right)$, effector memory $\left(\mathrm{CD} 4{ }^{+} \mathrm{CD} 44^{+} \mathrm{CD} 62 \mathrm{~L}^{-}\right)$ and central memory $\left(\mathrm{CD} 4^{+} \mathrm{CD} 44^{+} \mathrm{CD} 62 \mathrm{~L}^{+}\right) \mathrm{T}$ helper cells in the same mice as $(\mathrm{A})$.

(C) Representative FACS plots for CD44 and CD62L staining, gated on CD4 ${ }^{+}$cells.

(D) Quantification of $(C)$ represented as mean (red bar) $\pm S D$, from individual mice represented by circles.

(E, F) Splenic naïve $\left(\mathrm{CD} 8^{+} \mathrm{CD} 44^{\text {low }} \mathrm{CD} 2 \mathrm{~L}^{+}\right)$, effector memory $\left(\mathrm{CD} 8^{+} \mathrm{CD} 44^{+} \mathrm{CD} 62 \mathrm{~L}^{-}\right)$ and central memory $\left(\mathrm{CD} 8^{+} \mathrm{CD} 44^{+} \mathrm{CD} 2 \mathrm{~L}^{+}\right) \mathrm{CD}^{+} \mathrm{T}$ cells in the same mice as $(\mathrm{A})$.

(E) Representative FACS plots.

(F) Quantification of (E) represented as mean (red bar) $\pm S D$, from individual mice represented by circles.

(G) G-CSF, IFN $\gamma$ and TNF concentrations in plasma of non-infected (NI) and at the peak (day 7) of PcC infection in $G 6 p c 1^{A l b \Delta / \Delta}$ ( $\mathrm{N}=12$; purple circles) and $G 6 p C 1^{f / / f l}$ $(\mathrm{N}=11$; white circles) mice. Data represented as mean (red bar) $\pm \mathrm{SD}$, from individual mice, pooled from 2 independent experiments with similar trend.

(H) Alanine Aminotransferase (ALT) concentration in plasma of non-infected (NI) and at the peak (day 7) of $P c c$ infection in $G 6 p c 1^{A l b \Delta / \Delta}\left(\mathrm{N}=5\right.$; purple circles) and $G 6 p C 1^{\text {fl/fll }}$ 
$(\mathrm{N}=5$; white circles) mice. Circles represent individual mice, red bars mean values \pm $\mathrm{SD}$, from one experiment.

(I) H\&E staining of the liver from Pcc-infected G6pc $1^{A l b \Delta / \Delta}(\mathrm{N}=7)$ and $G 6 p C 1^{f / / f l}(\mathrm{~N}=5)$ mice. Dashed lines outline necrosis areas. Images are representative of 2 independent experiments. Scale bar: $100 \mu \mathrm{m}$.

$P$ values in $(B, D, F, G)$ determined using Two-Way ANOVA with Tukey's multiple comparison test and in $(\mathrm{H})$ using the Mann Whitney test. ns - non-significant; * $p<0.05 ;{ }^{* *}-p<0.01$.

Figure 5. Repression of HGP regulates Plasmodium behavior (see also Figure S5)

(A) Disease trajectories established by the relationship between circulating RBC and infected RBC (iRBC) numbers per $\mu \mathrm{L}$ of blood, during the 15-day course of PcC infection in $G 6 p c 1^{A / b \Delta / \Delta}\left(\mathrm{N}=15\right.$; purple lines) and $G 6 p C 1^{f / / f l}(\mathrm{~N}=12$; gray lines) mice. Purple circles indicate death.

(B) Maximum parasitemia (\% $\mathrm{iRBC}$ ), minimum RBC (i.e. anemia) and maximum iRBC (pathogen load) numbers per $\mu \mathrm{L}$ of blood, during the course of Pcc infection in the same mice as $(A)$. Data is represented as mean (red bars) \pm SEM, pooled from 3 independent experiments with similar trend. Circles represent individual mice.

(C) Erythropoietin concentration (mean $\pm \mathrm{SD}$ ) in plasma from $G 6 p c 1^{A l b \Delta / \Delta}(\mathrm{N}=12$; purple circles) and $G 6 p C 1^{f / / f l}(\mathrm{~N}=11$; white circles) mice, at the peak of Pcc infection (i.e. day 7). Data from 2 independent experiments. Circles represent individual mice.

(D) Combined Single-cell (sc) RNA UMAP projection of single-cell parasite transcriptomes in FACS-sorted iRBCs from G6pc1 $1^{\text {fl/tI }}$ and G6pc1 $1^{A / b \Delta / \Delta}$ mice. Each dot represents an individual parasite transcriptome. Colors and corresponding cluster numbers identify parasite developmental stages, according to 25 highest expressed transcripts and analogy to $P$. falciparum and $P$. berghei gene orthologues (Malaria Cell Atlas; https://www.sanger.ac.uk/tool/mca/).

(E) ScRNA UMAP projection of parasite transcriptomes in the FACS-sorted iRBCs from G6pc1 $1^{f / / f l}\left(\mathrm{n}=5294\right.$; left panel) and $G 6 p c 1^{A / b \Delta / \Delta}(\mathrm{n}=15543$ right panel) mice.

(F) Percentage of Pcc transcriptomes per cluster in FACS-sorted iRBCs from (D).

(G) RNA velocity analysis of Pcc transcriptomes in FACS-sorted iRBCs from (D). 
(H) Cluster-specific heatmap of differentially regulated genes (average $\log _{2}$ fold change) in the same FACS-sorted iRBCs as (D). Numbers correspond to Pcc gene identification (e.g. PCHAS_xxxx).

$P$ values in $(B, C)$ were determined using the Mann Whitney test. ns: non-significant; ${ }^{* * *}: p<0.001$.

Figure 6. Repression of HGP regulates Plasmodium virulence and gametocytogenesis (see also Figure S6)

(A) Quantification of hepatic mRNA encoding the virulence factors hmgb2 (PCHAS_072200; N=6 per genotype) and fam b (PCHAS_100100; N=4 per genotype). Data is represented as mean (red bars) \pm SD, pooled from 2 independent experiments with similar trend. Circles represent individual mice. Data for $h m g b 2$ and famb was analyzed 7 and 8 days after Pcc infection, respectively.

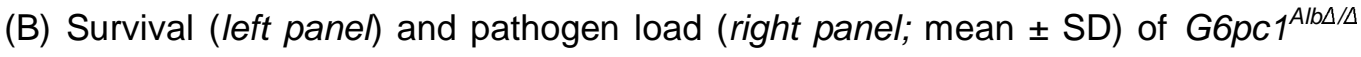
mice infected with $P c c$ iRBC from G6pc1 $1^{\text {Alb } \Delta / \Delta}$ (purple circles) vs. G6pc1 ${ }^{\text {fl/fll }}$ (light purple circles) mice ( $\mathrm{N}=6$ per group). Data pooled from 2 independent experiments with similar trend.

(C) Number of iRBC (mean $\pm \mathrm{SD}$ ) containing pyknotic parasites, quantified from Giemsa-stained thin blood smears of Pcc-infected G6pc1 $1^{A l b \Delta / \Delta}(\mathrm{N}=10)$ and $G 6 p C 1^{f / / H I}$ $(\mathrm{N}=8)$ mice. Data pooled from 2 independent experiments with similar trend.

(D) Disease trajectories established by the relationship between number of iRBC containing pyknotic parasites, calculated from Giemsa-stained thin blood smears in the same mice as in (C) and glycemia, during the 15-day course of Pcc. Purple circles indicate death.

(E-F) Glucose concentration regulates $P$. falciparum development and proliferation in vitro.

(E) Percentage of $P$. falciparum infected human RBC (iRBC) cultured in vitro under varying glucose concentrations (i.e. from $23-0 \mathrm{mmol} / \mathrm{L}$ ). Data calculated from Giemsa-stained thin blood smears and presented as mean \pm SEM, from three wells in 1 out of 3 independent experiments with similar trend.

(F) Percentage of $P$. falciparum iRBC containing morphologically healthy, aberrant or pyknotic parasites at $48 \mathrm{~h}$, from the same samples as in (E). Data is presented as 
mean \pm SEM, from three wells in1 out of 3 independent experiments with similar trend.

(G-H) Glucose regulates $P$. falciparum mitochondrial function in vitro.

(G) Representative histograms of mitochondrial membrane potential $\left(\Delta \Psi_{\mathrm{m}}\right.$; MitoTracker TM Deep Red FM) in P. falciparum-infected human RBC (iRBC) cultured for $24 \mathrm{~h}$ in vitro under varying glucose concentrations (i.e. from $11-0 \mathrm{mmol} / \mathrm{L}$ ). $P$. falciparum iRBC were identified as GFP and Hoechst fluorescent cells (See S6H). Gey histogram represents background MitoTracker ${ }^{\text {TM }}$ Deep Red FM staining in noninfected (Hoechst negative) RBC. Histograms are representative of 4 replicates, stained in duplicate, from one experiment.

(H) Quantification of Geometric Mean Fluorescence Intensity (mean \pm SEM) of MitoTracker ${ }^{\mathrm{TM}}$ Deep Red FM from (G). Dotted grey line indicates background signal in non-infected RBC, averaged from all replicates analyzed.

(I) Quantification of different Pcc development stages (mean \pm SD), identified morphologically from the same Giemsa-stained thin blood smears as $(C)$.

(J) Quantification of mRNA encoding gametocyte-specific genes in whole blood from $P c c$-infected $G 6 p c 1^{A l b \Delta / \Delta}(\mathrm{N}=4)$ vs. G6pc $1^{\text {fl/fll }}(\mathrm{N}=4-5)$ mice, 9 days after Pcc infection, normalized to PcC 18S mRNA. PCHAS_131600: Gamete egress and sporozoite traversal protein (gest), PCHAS_146530: Osmiophilic body protein (g377), PCHAS_111470: Gametogenesis essential protein 1 (gep1). Data is represented as mean (red bars) $\pm S D$, pooled from 2 independent experiments with similar trend. Circles represent individual mice.

$P$ values were determined in $(A, J)$ using One-tailed Unpaired Mann Whitney $U$ test, in (B) using Log-rank (Mantel-Cox) test (conservative) for survival and Two Way ANOVA for pathogen load, in $(\mathrm{C}, \mathrm{I})$ using Two Way ANOVA with Sidak's multiple comparison test for time course, in (E,F) using Two Way ANOVA with Tukey's multiple comparison test and in $(\mathrm{H})$ using Kruskal-Wallis tests with Dunn's multiple comparison test. $n s-$ non-significant; ${ }^{*}-p<0.05 ;{ }^{* *}-p<0.01 ;{ }^{* * *}-p<0.001 ;{ }^{* * *}$ $\mathrm{p}<0.0001$.

Figure 7. Glucose and temperature regulate Plasmodium behavior in vivo. (see also Figure S7)

(A) Representative infrared images from $\mathrm{N}=4-5$ mice per genotype, at steady state (naïve) and 7 days after Pcc infection. 
(B) Quantification of BAT, core body and tail temperatures in the same mice as (A).

Data is represented as mean (red bars) $\pm S D$, circles represent individual mice.

(C) Heat dissipation (calculated as the difference between tail base and core body temperature) in the same mice as (A). Data is represented as mean (red bars) $\pm S D$, circles represent individual mice.

(D-G) Ucp1-dependent thermogenesis is dispensable for thermoregulatory response to Pcc-infection.

(D) Core body temperature (mean $\pm \mathrm{SD})$ in $U c p 1^{-1-}(\mathrm{N}=4$; green circles) vs. control $\mathrm{Ucp}^{+/+}(\mathrm{N}=4$; white circles $)$ mice. Data from one experiment.

(E) Survival of Pcc-infected in the same mice as (D).

(F) Pathogen load (mean $\pm \mathrm{SD}$ ) in the same mice as (D).

(G) Blood glucose concentration, from the first 6 days of PCC infection, in the same mice as (D). Data is represented as mean (red bars) $\pm S D$, circles represent individual mice.

(H-J) Pcc-infection in C57BL/6 mice housed at standard (22 ${ }^{\circ} \mathrm{C}$; $\mathrm{N}=5$; blue dots) or thermoneutral $\left(31-32^{\circ} \mathrm{C} ; \mathrm{N}=4\right.$; red dots) husbandry condition.

$(\mathrm{H})$ Core body temperature (mean $\pm \mathrm{SD})$. Data from one experiment.

(I) Pathogen load (mean $\pm \mathrm{SD}$ ) in the same mice as $(\mathrm{H})$.

(J) Maximum parasitemia (\% iRBC), minimum RBC numbers and maximum pathogen load (iRBC/ $\mu \mathrm{L}$ ), in the same mice as $(\mathrm{H})$. Data is represented as mean (red bars) \pm SD. Circles represent individual mice.

(K-M) Pcc-infection in G6pc $1^{A l b \Delta / \Delta}$ mice housed at standard $\left(22^{\circ} \mathrm{C} ; \mathrm{N}=5\right.$; blue dots) or at thermoneutral $\left(31-32^{\circ} \mathrm{C} ; \mathrm{N}=7\right.$; red dots) husbandry conditions. Data pooled from 2 independent experiments with the same trend.

(K) Core body temperature represented as mean \pm SD.

(L) Pathogen load (mean $\pm \mathrm{SD}$ ) in the same mice as $(\mathrm{K})$.

(M) Maximum parasitemia (percentage $\mathrm{iRBC}$ ), minimum $\mathrm{RBC}$ numbers and maximum pathogen load ( $\mathrm{iRBC} / \mu \mathrm{L}$ ), in the same mice as $(\mathrm{K})$. Data is represented as mean (red bars) \pm SD. Circles represent individual mice.

$P$ values in $(B, C)$ determined using Two-Way ANOVA with Tukey's multiple comparison, $(\mathrm{D}, \mathrm{F}, \mathrm{H}, \mathrm{I}, \mathrm{K}, \mathrm{L})$ determined using Two-Way ANOVA with Sidak's multiple comparison, in (E) using Log-rank (Mantel-Cox) test (conservative) and in (G, J, M) 
using Mann Whitney test. $n s-$ non-significant; ${ }^{*}-p<0.05 ;{ }^{* *}-p<0.01 ;{ }^{* *}-p<0.001$; $* \star \star * *-p<0.0001$.

\section{SUPPLEMENTARY FIGURE LEGENDS}

Figure S1. HGP controls glycemia in response to Pcc infection. (Related to Figure 1).

(A) Pyruvate tolerance test (PTT) in control (Ctrl.; fasted overnight; $\mathrm{N}=4$ ) and PcCinfected (i.e. peak of infection, day 7; N=5) C57BL6 mice, at the times indicated after pyruvate administration (left panel) and corresponding area under the curve (right panel). Data represented as mean $\pm \mathrm{SD}$, from one experiment.

(B) Incidence of seizures after insulin administration in control and Pcc-infected C57BL6 mice. Same mice as Fig. 1F.

(C) Blood glucose concentration, represented as mean $\pm \mathrm{SD}$, in Pcc-infected $G 6 p c 1^{A l b \Delta / \Delta}\left(\mathrm{N}=15\right.$; purple circles) and $G 6 p C 1^{\text {fl/fll }}(\mathrm{N}=12$; white circles) mice. Same mice as Fig. 1G-J. Gray values are the proportion of surviving over total number of mice, at indicated time points.

(D) Insulin concentration in plasma of $G 6 p c 1^{A \mid b \Delta / \Delta}\left(\mathrm{N}=5\right.$; purple circles) and $G 6 p C 1^{f|| f \mid}$ $(\mathrm{N}=5$; white circles) mice at the peak of Pcc infection (i.e. day 7). Data represented as mean \pm SD from one experiment. Gray area: physiologic range.

(E-J) Disease parameters in same mice as Fig. 1G-J.

(E) Core body temperature, represented as mean \pm SD.

(F) Disease trajectories established by the relationship between core body temperature and parasite density (iRBC/ $\mu \mathrm{L})$. Circles represent death.

(G) Minimum core body temperature throughout Pcc infection. Data represented as mean (red bars) \pm SEM. Circles represent individual mice.

(H) Percentage of initial body weight. Data is represented as mean \pm SEM. Gray values are the proportion of surviving over total number of mice, at indicated time points.

(I) Disease trajectories established by the relationship between percentage of initial body weight and number of iRBC per $\mu \mathrm{L}$. Circles represent death.

(J) Minimum percentage of initial body weight throughout PCC infection. Data represented as mean (red bars) \pm SEM. Circles represent individual mice.

$P$ values determined in: (A) using Two-Way ANOVA with Tukey's multiple comparison test for Glucose concentration and, $t$ test for AUC, in (B) using Log-rank 
(Mantel-Cox) test (conservative), in (D,G,J) using Mann-Whitney $U$ test, $(E, H)$ using Two-Way ANOVA with Sidak's multiple comparison test. ns - non-significant; ${ }^{*} p<0.05 ;{ }^{* *} p<0.01 ;{ }^{* * *} p<0.001$.

Figure S2. HGP controls host EE during Plasmodium infection. (Related to Figure 2)

(A) Average of fine movements (i.e. non-directed ambulatory motion, expressed as: All distances traveled (i.e. Total Activity) - Directed ambulatory locomotion)) in the period highlighted by light blue in (Fig. $2 A$ ), segregated into one light/dark cycle. Data represented as mean \pm SEM, from the same mice as Fig. $2 A-H$.

(B-H) Metabolic and behavioral parameters of naïve G6pc $1^{A l b \Delta / \Delta}(\mathrm{N}=4$; purple circles) and $G 6 p C 1^{f / / f l}(\mathrm{~N}=4$; white circles) mice, represented as mean $\pm \mathrm{SEM}$, pooled from 2 independent experiments.

(B) Energy expenditure (EE) and (C) mean hourly EE, in the 3 day-period represented in $(B)$, segregated into daily light/dark cycle.

(D) Average of food intake in the 3 days time-period represented in (B), segregated into daily light/dark cycle.

(E) Respiratory exchange ratio (RER) and $(F)$ mean $R E R$, in the 3 day-period represented in $(E)$, segregated into daily light/dark cycle.

(G) Means $\mathrm{VCO}_{2}$ in the 3 day-period represented in $(\mathrm{E})$, segregated into daily light/dark cycle.

(H) Means $\mathrm{VO}_{2}$ in the 3 day-period represented in $(\mathrm{E})$, segregated into daily light/dark cycle.

(I-N) Metabolic and behavioral parameters of C57BL/6 mice, receiving heme ( $\mathrm{N}=4$; brown circles) or control PPIX ( $\mathrm{N}=4$; white circles) at the time indicated by the arrows, from the same mice as Fig. $2 I-P$.

(I) Fine movement (i.e. non-directed ambulatory motion) and ( $\mathrm{J}$ ) Means of fine movements in the $24 \mathrm{~h}$ period highlighted by light blue in (I), segregated into one light/dark cycle.

(K) $\mathrm{VO}_{2}$ and (L) Means of $\mathrm{VO}_{2}$, corresponding to the $24 \mathrm{~h}$ period highlighted by light blue shading in $(K)$, segregated into one light/dark cycle.

(M) $\mathrm{VCO}_{2}$ and $(\mathrm{N})$ average $\mathrm{VCO}_{2}$ in the $24 \mathrm{~h}$ period highlighted by light blue shading in (M), segregated into one light/dark cycle. 
(O) Glucose concentration after pyruvate administration (2mg/g of BW) test in C57BL6 mice receiving heme $(\mathrm{N}=4)$ or vehicle controls $(\mathrm{N}=5)$. Mean glycemia represented as mean $\pm S D$, from one experiment.

$P$ values in $(\mathrm{N})$ were determined using student t-test and in the remaining panels using Two-Way ANOVA with Sidak's multiple comparison test. $n s-$ non-significant; * $p<0.05 ;{ }^{* *} p<0.01 ;{ }^{* * * *} p<0.0001$.

Figure S3. Labile heme recapitulates the repression of HGP in response to Plasmodium infection. (Related to Figure 3)

(A) Principal component analysis (PCA) of 18,136 transcripts differentially expressed in whole livers from C57BL/6 mice subjected to fasting (fasted overnight; 15h; $\mathrm{N}=4$ ), receiving heme $(30 \mathrm{mg} / \mathrm{Kg}$, overnight; $\mathrm{N}=3$ ) or at the peak of Pcc infection (i.e. day 7; $\mathrm{N}=4$ ).

(B) Scatter plot of the 18,136 transcripts differentially expressed in the liver of the same mice as (A). Plotting log2 fold change (FC) of Pcc infection vs. fasting (x-axis) against log2FC of heme administration vs. fasting (y-axis), was used to highlight shared transcripts (adjusted p-value <0.05). Upper right quadrant contains shared up-regulated transcripts (1551), lower left quadrant contains shared downregulated transcripts (1747). Shared transcripts had an absolute log2 fold change higher than 1, compared to fasted controls, in both pairwise comparisons. Broken red lines marks $\log F C=1$.

(C) Venn diagram of pathways (i.e. GO terms database) downregulated by heme administration and by Pcc-infection, as compared to fasted control mice.

(D) Functional enrichment analysis of the 12 up-regulated pathways (i.e. GO terms database) with highest enrichment scores (-log10 adjusted p-value) in Pcc infected vs. control fasted mice.

(E) Functional enrichment analysis of the 12 up-regulated pathways (i.e. GO terms database) with highest enrichment score (-log10 adjusted $p$-value) in mice receiving heme vs. control fasted mice.

(F) Venn diagram of pathways, using GO terms database, up-regulated by heme administration and by Pcc-infection, as compared to control fasted mice.

(G) Functional enrichment analysis of DNA-binding motifs (i.e. TRANSFAC database) in the regulatory regions of shared transcripts downregulated by heme 
administration and PCC-infection, compared with control fasted mice respectively. Left panel illustrates DNA-binding motifs with the highest enrichment score $(-\log 10$ adjusted p-value)(left panel). Right panel illustrates DNA-binding motifs with the highest enrichment score (-log10 adjusted p-value) downregulated exclusively in response to heme administration or to Pcc-infection.

(H) Venn diagram representing the number and percentage of DNA-binding sites present in the regulatory regions of shared transcripts downregulated by heme administration and PCC-infection, compared with fasted control mice, respectively.

(I) Transcription factor motif prediction analysis (i.e. JASPAR) of mouse G6pc1 promoter $(-320$ to +20$)$, highlighting DNA-binding sites also present in the regulatory regions of shared transcripts downregulated by heme administration and PCCinfection, compared with fasted control mice respectively (as in $\mathrm{G}$ ).

Figure S4. Repression of HGP exerts no effect on monocyte/macrophages in response to Pcc infection. (Related to Figure 4)

(A-D) Analyzes of splenic monocyte/macrophages from naïve ( $\mathrm{N}=4$ per genotype) and Pcc-infected (i.e. peak of infection, day $7 ; \mathrm{N}=6$ per genotype) G6pc1 $1^{\text {Alb } \Delta / \Delta}$ (purple dots) and $\mathrm{G} 6 p C 1^{f / / f l}$ (white dots) mice. Data is represented as mean (red bar) $\pm \mathrm{SD}$ from 2 independent experiments with similar trend. Circles represent individual mice. Same mice as in Fig. S4A-F.

(A) Representative FACS plots for splenic CD11b and F4/80 staining (i.e. gated on (CD19'Ly6G').

(B) Quantification of splenic monocyte/conventional dendritic cells (CD11b $\left.{ }^{+} \mathrm{F} 4 / 80^{-}\right)$.

(C) Quantification of splenic monocytes $\left(\mathrm{CD} 11 \mathrm{~b}^{+} \mathrm{F} 4 / 80^{\mathrm{int}}\right)$.

(D) Quantification of splenic red pulp macrophages (CD11b-F4/80+).

(E) Quantification of circulating neutrophils in $G 6 p c 1^{A / b \Delta / \Delta}$ (purple dots; $N=5$ ) and

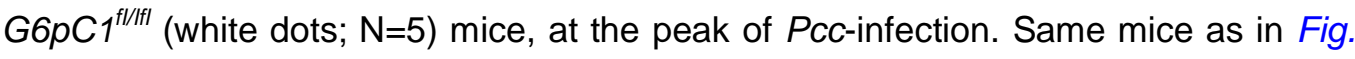
$5 C$. Data is represented as mean (red bar) $\pm S D$ from one experiment. Circles represent individual mice.

(F) Cytokine/chemokine concentration $(\mathrm{pg} / \mathrm{mL})$ in the plasma of naïve ( $\mathrm{N}=5$ per genotype) and at the peak (i.e. day 7) of $P c c$ infection in $G 6 p c 1^{A l b \Delta / \Delta}(\mathrm{N}=12$; purple circles) and $G 6 p C 1^{f / / f l}(\mathrm{~N}=11$; white circles) mice. Same mice as in Fig. 4G. Data is represented as mean $\pm \mathrm{SD}$ and from 2 independent experiments with similar trend. 
$P$ values in (B-D, F) were determined using Two-Way ANOVA with Tukey's multiple comparison test. In E using unpaired t test. $n s$ - non-significant; ${ }^{*}-p<0.05$.

Figure S5. Repression of HGP regulates Plasmodium behavior. (Related to Figure 5)

(A) Hemograms at the peak of Pcc infection (i.e. day 7) in $G 6 p c 1^{A l b \Delta / \Delta}$ ( $N=5$; purple) and $G 6 p C 1^{f / / f l}(\mathrm{~N}=5$; white) mice (same mice as in Fig. $5 C$ ), depicting erythrocyte numbers, hemoglobin concentration, hematocrit, RBC mean corpuscular volume (MCV), RBC mean corpuscular hemoglobin $(\mathrm{MCH})$, RBC mean corpuscular hemoglobin concentration ( $\mathrm{MCHC}$ ) and $\mathrm{RBC}$ distribution width (RDW). Data represented as mean (red bar) \pm SD from one experiment. Circles represent individual mouse. Gray rectangles indicate range of reference values for steady state. $\mathrm{P}$ values were determined using unpaired $t$ test. $n s$ - non-significant; * $p<0.05,{ }^{* *}-p<0.01$.

(B) Expression pattern of parasite stage-specific transcripts across the combined single-cell (sc) RNA UMAP projection of transcriptomes in FACS-sorted iRBCs from G6pc1 $1^{f / f l}$ and G6pc1 $1^{A l b \Delta / \Delta}$ mice. In ring stages: enolase (eno, PCHAS_1215000) and succinate dehydrogenase subunit 4 (sdh4, PCHAS_1209400); in trophozoites: phosphoglycerate kinase (pgk, PCHAS_0823700) and fam a (PCHAS_120120); in schizonts: rhoptry neck protein 2 (ron2, PCHAS_1319000) and merozoite surface protein 9 (msp9, PCHAS_1445500), in sexually committed (SC) rings: carbon catabolite repression-negative on TATA-less, (CCR4-Not) subunit 2 (not2, PCHAS_0924800) and in gametocytes: SOC protein 3 (soc3, PCHAS_1307700).

(C) Combined UMAP projection of mouse single RBC transcriptomes in the same FACS-sorted iRBCs from G6pc1 $1^{f / / f l}$ and $G 6 p c 1^{A / b \Delta / \Delta}$ mice in (B). Each dot represents a transcriptome from one individual RBC.

(D) Functional enrichment analysis of parasite pathways (i.e. GO terms database) down regulated in Cluster 3 (i.e. sexually-committed rings) in FACS-sorted iRBCs from $G 6 p c 1^{A / b \Delta / \Delta}$ vs. G6pc1 $1^{f / / f l}$ mice.

(E) Functional enrichment analysis of parasite pathways (i.e. GO terms database) upregulated in Cluster 4 (i.e. trophozoites) in FACS-sorted iRBCs from G6pc1 $1^{A l b \Delta / \Delta}$ vs. G6pc1 $1^{f / f t}$ mice. 
(F) Functional enrichment analysis of parasite pathways (i.e. GO terms database) upregulated in Cluster 7 (i.e. rings) in FACS-sorted iRBCs from G6pc $1^{\text {Alb } \Delta / \Delta}$ vs. G6pc1 $1^{\text {fllfl }}$ mice.

Figure S6. Repression of HGP reduces Plasmodium virulence and induces gametocytogenesis. (Related to Figure 6)

(A, B) Repression of HGP lowers Pcc virulence. G6pc1 $1^{A l b \Delta / \Delta}$ mice were infected with $P c c$ iRBC from $G 6 p c 1^{A / b \Delta / \Delta}$ (purple circles) vs. G6pc1 $1^{f / / f l}$ (light purple circles) mice ( $\mathrm{N}=6$ per group) (same mice as Fig. 6B). Data pooled from 2 independent experiments with similar trend.

(A) Body temperature (left panel) and minimum body temperature throughout the 15days of $P c c$ infection (right panel) represented as mean \pm SD. Circles in right panel represent individual mice and red bars represent mean.

(B) Glycemia (left panel) and minimum glycemia throughout the 15 days of PcC infection (right panel) presented as mean \pm SD. Circles in right panel represent individual mice and red bars in right panel mean.

(C, D) Representative Giemsa-stained thin blood smears of $G 6 p c 1^{f / / f l}(\mathrm{C} ; \mathrm{N}=14)$ and G6pc1 $1^{A l b \Delta / \Delta}(\mathrm{D} ; \mathrm{N}=17)$ mice, 7 days after Pcc infection. Data representative of 3 independent experiments, with similar trend. Parasite stages were identified based on morphology. Arrows highlight parasites, purple text: blood glucose concentration. Scale bar is $2 \mu \mathrm{m}$.

(E-H) Glucose concentration regulates $P$. falciparum development and proliferation in vitro.

(E) Representative Giemsa-stained thin blood smears of $P$. falciparum infected human RBC (iRBC) cultured in vitro under varying glucose concentrations vs. control media ( 11 $\mathrm{mmol} / \mathrm{L}$ Glucose). Indented square (Oh) represents original seeded culture. Filled arrowheads indicate healthy parasites, empty arrowheads aberrant parasites and asterisks pyknotic parasites. Images representative of 3-4 replicates in 3 independent experiments. Scale bar is $2 \mu \mathrm{m}$.

$(\mathrm{F}, \mathrm{G})$ Percentage of $P$. falciparum iRBC cultured in vitro for $24 \mathrm{~h}(\mathrm{~F})$ and $72 \mathrm{~h}(\mathrm{G})$, under varying glucose concentrations $(23-0 \mathrm{mmol} / \mathrm{L})$, containing morphologically healthy, aberrant or pyknotic parasites. Data is from the same experiment as in (E) and presented as mean \pm SEM, from 3 wells in 1 out of 3 independent experiments with similar trend. 
(H) Gating strategy used to identify $P$. falciparum infected human RBC (iRBC). Cells were gated based on size and granularity (FCS-A vs. SSC-A plot). Single cells were identified based on FSC-A vs. FSC-H profile, and GFP or Hoechst (DNA content) signals were used to identify $P$. falciparum iRBC.

$P$ values in $(F, G)$ and for core body temperature and blood glucose in $(A, B)$ were determined using Two-Way ANOVA with Tukey's multiple comparison test and in $(A, B)$ for minimum core body temperature and blood glucose using unpaired t test. ns - non-significant; ${ }^{*}-p<0.05 ;{ }^{* *}-p<0.01 ;^{* * *}-p<0.001 ;^{* * * *}-p<0.0001$.

Figure S7. Host glycemia and core body temperature regulate Plasmodium behavior in vivo. (Related to Figure 7 )

(A-G) Hyperglycemia promotes Pcc expansion. hyperglycemia was induced by the administration of streptozocin (STZ) prior to Pcc infection in C57BL/6 mice STZ (N=3; purple dots). Controls (Ctr.) received vehicle (PBS; $\mathrm{N}=5$; lilac dots). Red bars in (C) indicate mean. Data from one experiment.

(A) Blood glucose concentration presented as mean \pm SD.

(B) Pathogen load presented as mean \pm SD.

(C) Maximum percentage of $\mathrm{iRBC}$, minimum $\mathrm{RBC}$ count and maximum count of iRBC. Data represented as mean (red bars) \pm SD. Circles correspond to individual mice.

(D) Survival.

(E) Individual relationships (i.e. disease trajectories) between body temperature and pathogen load during the entire course of Pcc infection.

(F) Individual relationships (i.e. disease trajectories) between percentage of initial body weight and pathogen load during the entire course of Pcc infection.

(G) Individual relationships (i.e. disease trajectories) between the number of circulating $\mathrm{RBC}$ and pathogen load during the entire course of Pcc infection.

$(\mathrm{H}-\mathrm{K})$ Core body temperature regulates Pcc expansion. Pcc-infected C57BL/6 mice, housed at standard husbandry $\left(22^{\circ} \mathrm{C}\right.$; blue circles; $\left.\mathrm{N}=5\right)$ or at thermoneutral condition $\left(31-32^{\circ} \mathrm{C}\right.$; red circles; $\left.\mathrm{N}=4\right)$. Circles in $(\mathrm{I}-\mathrm{K})$ indicate death. Data from one experiment. Same mice as Fig. 7 -H-J.

(H) Survival. 
(I) Individual relationships (i.e. disease trajectories) between Glycemia and pathogen load during the entire course of Pcc infection.

(J) Individual relationships (i.e. disease trajectories) between percentage of initial body weight (compared to non-infected) and pathogen load during the entire course of Pcc infection.

(K) Individual relationships (i.e. disease trajectories) between the number of circulating RBC and pathogen load during the entire course of Pcc infection.

(L-O) Glycemia and core body temperature regulates Pcc expansion. Pcc-infected of $P c c$-infected G6pc1 $1^{A l b \Delta / \Delta}$ mice housed at standard husbandry $\left(22^{\circ} \mathrm{C}\right.$; violet circles; $\mathrm{N}=5)$ or at thermoneutral condition $\left(31^{-32^{\circ}} \mathrm{C}\right.$; purple circles; $\mathrm{N}=7$ ). Circles in $(\mathrm{M}-\mathrm{O})$ indicate death. Data pooled from 2 independent experiments. Same mice as Fig. 7K-M.

(L) Survival.

(M) Individual relationships (i.e. disease trajectories) between Glycemia and pathogen load during the entire course of Pcc infection.

(N) Individual relationships (i.e. disease trajectories) between percentage of initial body weight and pathogen load during the entire course of PcC infection.

(O) Individual relationships (i.e. disease trajectories) between the number of circulating $\mathrm{RBC}$ and pathogen load during the entire course of Pcc infection.

$P$ values determined in $(A, B)$ using Two-Way ANOVA with Sidak's multiple comparison test, in (C) using Mann Whitney test, in $(D, H, L)$ using Log-rank (MantelCox) test (conservative). ns - non-significant; ${ }^{*} \mathrm{p}<0.05$; ${ }^{* *}-\mathrm{p}<0.01 ;{ }^{* * *} \mathrm{p}<0.001$; ${ }^{* * *} p<0.0001$. 


\section{STAR METHODS}

Key Resources TABLE (see Key Resources file)

\section{CONTACT FOR REAGENT AND RESOURCE SHARING}

Further information and requests for resources and reagents should be directed to and will be fulfilled by the Lead Contact, Miguel P. Soares

(mpsoares@igc.gulbenkian.pt).

\section{EXPERIMENTAL MODEL AND SUBJeCt DetAILS}

\section{Mice and Conditional allele deletions}

Mice were bred and maintained under specific pathogen-free (SPF) conditions at the Instituto Gulbenkian de Ciência (IGC) or at the Jena University Hospital. Mice were housed at standard vivarium temperature $\left(22^{\circ} \mathrm{C}\right)$ or at thermoneutrality $\left(31-32^{\circ} \mathrm{C}\right)$ in a 12-hour light/dark cycle with free access to water and standard chow pellets. Experimental protocols were approved by the Instituto Gulbenkian de Ciência Ethics Committee/ORBEA and the Portuguese National Entity (Direcção Geral de Alimentação e Veterinária) or by the Jena University Hospital regional animal welfare committee (Registration number: 02-048/16, Thuringian State Office for Consumer Protection and Food Safety). Experimental procedures were performed according to the Portuguese or the German legislation on protection of animals and European (Directive 2010/63/EU) legislations. C57BL/6J mice were obtained from the IGC or the Jena University Hospital animal facilities. C57BL/6 Sa ${ }^{\mathrm{CreERT2Nt} G 6 p c 1^{\mathrm{fl} / \mathrm{fl}}}$ (i.e. G6pc1 $1^{\text {Albfl/fl) }}$ mice and littermate control G6pc1 $1^{f / f l}$ mice were previously described (Mutel et al., 2011; Weis et al., 2017). Conditional deletion of the G6pc1 ${ }^{\text {tilfl }}$ allele in hepatocytes was induced by Tamoxifen administration (i.p., $10 \mathrm{mg} / \mathrm{mL}, 100 \mu \mathrm{L}$; Sigma), daily for 5 days, starting at 8-week after birth as described (Mutel et al., 2011; Weis et al., 2017). The resulting G6pc1 $1^{A l b \Delta / \Delta}$ mice were used 2 weeks after deletion. Ucp $1^{-/}\left(\mathrm{B} 6.129-U c p 1^{\mathrm{tm} 1 \mathrm{Kz}} / \mathrm{J}\right)$ mice were obtained from The Jackson Laboratory (JAX \#003124) and breed in heterozygosity at the IGC animal house. Wild type littermates were used as controls.

\section{Plasmodium}

Mice were infected with the following Plasmodium chabaudi chabaudi ( $P c c)$ strains: PcAS (Reece and Thompson, 2008) and transgenic GFP-expressing PcAS (PcAS-GFP ${ }_{\mathrm{ML}}$ )(Marr et al., 2020; Ramos et al., 2019). In vitro assays were performed 
using a transgenic GFP-expressing, laboratory-adapted $P$. falciparum line 3D7-GFP (Pf-3D7-GFP; MRA-1029, MR4, ATCC® Manassas Virginia).

\section{METHOd DETAILS}

\section{Plasmodium chabaudi chabaudi infection and disease assessment}

Infections were performed as described (Ramos et al., 2019). Briefly, blood was harvested from an infected mouse carrying $\sim 10 \%$, parasitemia, diluted in PBS to reach $\sim 1 \times 10^{7} \mathrm{iRBC} / \mathrm{mL}$ and an inoculum of $200 \mu \mathrm{L}\left(\sim 2 \times 10^{6} \mathrm{iRBC}\right)$ was administered (i.p.). Disease progression was monitored daily, from day zero (D0) onwards quantifying anorexia, body weight (Ohaus ${ }^{\circledR}$ CS200 scaler, Sigma Aldrich), core (i.e. rectal) body temperature (Rodent thermometer; BIO-TK8851, Bioset) and blood glucose concentration (Accu-CHECK Performa glucometer, Roche), as well as parasitemia and number of RBC, as described (Ramos et al., 2019).

\section{Food intake}

Steady-state daily food intake was quantified for 2 days before infection, and subsequently throughout the course of infection. Briefly C57BL/6 mice were housed in individual cages with free access to water and standard chow pellets. Food pellets were weighed (Ohaus ${ }^{\circledR}$ CS200 scaler, Sigma Aldrich) daily at 6:00pm and daily food consumption was calculated as follows: Pellet Mass 24 hrs before - Pellet Mass $24 \mathrm{hrs}$ after $=$ daily food intake.

\section{Infrared Temperature Measurements}

BAT and tail temperatures were measured from digital images obtained using a infrared camera (FLIR E96: Compact-Infrared-Thermal-Imaging-Camera; FLIR Systems; West Malling, Kent, UK), analyzed with a software package (FLIR Tools ${ }^{\circledR}$ Software, FLIR Systems; West Malling, Kent, UK) as described (Blankenhaus et al., 2019). Before acquiring images, mice were anesthetized (1-2\% Isoflurane) and the interscapular area was shaved, after which mice were allowed to recover for at least 24 hours. Several infrared images of the BAT and Tail base were taken while mice were allowed to move freely on a cage lid. The analysis software was used to determine the average temperature of a selected region of the interscapular area and tail base across 3-4 images from the same animal. Images were acquired in noninfected, or Pcc infected (Day 7). 


\section{Pathogen load}

Number of RBC per $\mu \mathrm{L}$ of mouse blood was quantified by flow cytometry (FACSCalibur analyzer; BD Biosciences) using a standard concentration of reference

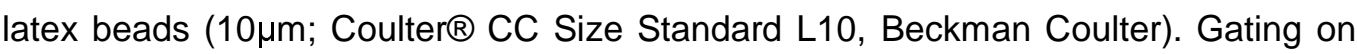
RBC was based on size vs. granularity and on bead population. Percentage of PCC AS iRBCs (i.e., parasitemia) was determined manually by optical microscopy, counting RBC in 4 fields of Giemsa-stained blood smears (1000x magnification). Percentage of PcAS-GFP $\mathrm{M}^{-}$-iRBC was determined by flow cytometry, according to the percentage of RBC expressing GFP $\left(\mathrm{GFP}^{+}\right)$. Pathogen load was determined as: Parasitemia $x$ RBC number and is expressed as $\mathrm{iRBC} / \mu \mathrm{L}$. Disease trajectories were plotted using disease parameters $v s$. parasite density, daily for individual mice, over the entire period of the infection, as described (Ramos et al., 2019).

\section{Plasmodium falciparum in vitro culture}

Laboratory-adapted Plasmodium falciparum (Pf)-3D7-GFP was co-cultured $\left(37^{\circ} \mathrm{C}\right.$; $95 \%$ humidity, $5 \%$ of $\mathrm{CO}_{2}$ ) with human erythrocytes from healthy donors $(5 \%$ hematocrit), replacing human serum was replaced by $0.5 \%$ AlbuMAXII (Invitrogen ${ }^{\mathrm{TM}}$, Thermo Fisher Scientific), as described (Santos et al., 2015). Briefly, Pf-3D7-GFP cultures were synchronized using 5\% D-Sorbitol (Sigma-Aldrich), returned to standard culture conditions until parasite RBC reinvasion, synchronized twice again, with a $6 \mathrm{~h}$ interval and returned to culture (Lobo et al., 2018). Parasites at the schizont stage were suspended, layered on a $70 \%$ Percoll (Sigma-Aldrich), centrifuged (1000g; 15 min. no brake), collected from the upper layer of Percoll cell suspension, washed (PBS) and incubated in standard culture conditions until RBC reinvasion (Santos et al., 2015). Ring stage parasites ( $<10 \mathrm{~h}$ post-invasion) were diluted to $\cong 0,8 \%$ parasitemia and $3 \%$ hematocrit in RPMI 1640 without glucose (Gibco ${ }^{\mathrm{TM}}$, Thermo Fisher Scientific) and seeded on a 24-well plate. Parasites were then cultured under increasing D-glucose concentrations (Sigma-Aldrich, Thermo Fisher Scientific). Slides were prepared at 24,48 and $72 \mathrm{~h}$ and stained with Giemsa. The remaining of the parasites in the same culture were washed (PBS/BSA) and analyzed by flow cytometry (described below).

\section{Plasmodium blood stages assessment}

PcC ring, trophozoite, schizont and gametocyte stages were quantified in Giemsastained blood smears by morphological assessment, based on DNA content, parasite 
size and hemozoin deposition. Pyknotic parasites were identified by their condensed chromatin mass without discernable cellular structures (i.e. cytoplasm, food vacuole) and hemozoin. The percentage of each Plasmodium stage was calculated over total number of $\mathrm{iRBC}$ and density was calculated as described above.

In P. falciparum assays, aberrant Pf-3D7-GFP parasites presented morphologically a compromised cell structure or delayed development while pyknotic Pf-3D7-GFP had condensed chromatin without discernable cytoplasm, food vacuole or hemozoin. These were compared to healthy parasites grown in a control media (RPMI1640, Biowest, routinely used for $P$. falciparum growth, glucose $\sim 11 \mathrm{mmol} / \mathrm{L}$ concentration).

Blood smear images were acquired on a Zeiss Imager Z2/ApoTome.2 system, equipped with an Axiocam 105 color camera, using the 100x 1.4NA Oil immersion objective, in a 5x5 tile stitched with Zeiss's ZEN v3.1 and analyzed using the Fiji Software (ImageJ). Background in parasite RGB images was corrected using the Colour Correct plugin for Fiji, contributed by Gabriel Landini (https://github.com/landinig/lJ-Colour Correct/blob/main/colour correct.zip).

\section{Plasmodium virulence assay}

Pcc AS parasites were adoptively transferred from G6pc1 $1^{A l b \Delta / \Delta}$ vs. G6pc1 $1^{f / f l}$ mice into G6pc1 $1^{A l b \Delta / \Delta}$ or C57BL6/J mice. Briefly, PcC infection was monitored at the peak of infection (D6-D7) to determine blood glucose concentration and the presence of pyknotic parasites in Giemsa-stained blood smears. At the time point when G6pc1 $1^{A l b \Delta / \Delta}$ mice presented severe hypoglycemia and the highest number of RBC containing pyknotic parasites, blood was collected from both $G 6 p c 1^{A l b \Delta / \Delta}$ and G6pc1 ${ }^{f / f f l}$ control mice. The blood of each donor animal was diluted so that an estimated 1.2-1.5 $\times 10^{6}$ iRBC were passively transferred (i.p.) into recipient G6pc1 $1^{A l b \Delta / \Delta}$ or C57BL6/J mice. These were monitored daily for survival and disease assessment, as described above.

\section{Glucose, Pyruvate and Insulin Tolerance Tests}

Glucose (GTT; Sigma; 1 mg/g BW), pyruvate (PTT; sodium Pyruvate, Sigma; 2mg/g BW) and insulin (ITT; Humulin R U-100 UI/mL; 2 Units per mouse, Eli Lilly) tolerance tests were performed on Pcc infected (at day 7) vs. control overnight fasted C57BL6 male mice or on overnight-fasted $\mathrm{C} 57 \mathrm{BL} / 6$ mice subsequently receiving heme (i.p., $30 \mathrm{mg} / \mathrm{Kg} \mathrm{BW}$ ) or vehicle (PBS) and tested after 10 hours. Blood was drawn from a 
tail cut and blood glucose concentration was measured using a glucometer (AccuCheck System, Roche) at 0, 15, 30, 60, 90, and 120 mins after injection.

\section{Heme administration}

Hemin (Frontier Scientific) stock solutions were prepared, as described (Ramos et al., 2019). Briefly, hemin was dissolved in $0.2 \mathrm{~N} \mathrm{NaOH}$ and buffered to $\mathrm{pH} 7.4$ using $0.2 \mathrm{~N} \mathrm{HCl}$. After filtration $(70 \mu \mathrm{m}$ cell strainer) to remove precipitates, a stock solution was stored at $-80^{\circ} \mathrm{C}$ up to one month. Heme absorbance was determined using a spectrophotometer (SmartSpec 3000) at $\lambda_{405 \mathrm{~nm}}$ and concentration was calculated using extinction coefficient $\left(E_{m M}=85.82\right)$, following the Lambert-Beer law $\left(\mathrm{A}_{405 \mathrm{~nm}}=\varepsilon \mathrm{cl}\right)$. Heme was diluted in PBS and administered (i.p., $\left.30 \mathrm{mg} / \mathrm{Kg} \mathrm{BW}\right)$.

\section{Promethion behavioral and phenotyping system}

Promethion Core (Sable Systems, USA) was used to measure indirect calorimetry. Mice were housed on a 14/10 h light/dark cycle with controlled temperature and humidity. After 2 days of acclimation phase, Heme/PPIX (Frontier Scientific, USA) were administered intraperitonially (i.p. $30 \mathrm{mg} / \mathrm{Kg}$ ). The recording continued for the following 7 days. The system consists of a standard GM-500 cage with a food hopper and a water bottle connected to load cells (2 mg precision) with $1 \mathrm{~Hz}$ rate data collection. Additionally, the cage contains a red house enrichment. Ambulatory activity was monitored at $1 \mathrm{~Hz}$ rate using an XY beam break array (1 $\square \mathrm{cm}$ spacing). Oxygen, carbon dioxide and water vapor were measured using a CGF unit (Sable Systems). This multiplexed system operated in pull $\square$ mode. Air flow was measured and controlled by the CGF (Sable Systems) with a set flow rate of $2 \square \mathrm{L} / \mathrm{min}$. Oxygen consumption and carbon dioxide production were reported in milliliters per minute (mL/min). Energy expenditure was calculated using the Weir equation (Weir, 1949) and Respiratory Exchange Ratio (RER) was calculated as the ratio of $\mathrm{VCO}_{2} / \mathrm{VO}_{2}$. Raw data was processed using Macro Interpreter v2.41(Sable Systems). Similar setup was used to assess the metabolic parameters of Pcc infected mice, except for the use of a 12/12 h light/dark cycle. Briefly, naïve G6pc1 $1^{A l b \Delta / \Delta}$ and $G 6 p c 1^{f / / f l}$ mice were allowed to acclimatize within the cages for 3 days, and were taken out for infection. Mice were subsequently returned to the cages and monitored from days 6-9 of infection. 


\section{Luciferase Assays}

HepG2 cells were seeded onto 6-well plates and transfected $24 \mathrm{~h}$ thereafter $(60 \%-$ $80 \%$ confluence) with full or truncated forms of pGL2B-G6PC (containing $-1320 /+60$, $-320 /+60,-80 /+60$, from the rat G6pc1 promoter, kind gift from Amandine GautierStein; Université Claude Bernard Lyon, France)(Rajas et al., 2002) or the empty vector pGL2B alone using Lipofectamine LTX Reagent with PLUS Reagent (Invitrogen, Thermo Scientific), according to manufacturer's instructions. A Renilla Luciferase-expressing vector (kind gift from Amandine Gautier-Stein; Université Claude Bernard Lyon, France)(Rajas et al., 2002) was co-transfected as transfection control. Forty-eight hours thereafter cells were treated with heme $(40 \mu \mathrm{M} ; 16 \mathrm{~h} ; 10 \%$ FBS 1\%PS DMEM) and collected for luciferase activity assessment, determined using the Luciferase assay system Dual-Glo (Promega), according to manufacturer's instructions. Luminescence was measured using a microplate reader (Glomax, Promega). Firefly Luciferase was normalized to Renilla and Luciferase activity is expressed as relative light units (RLU) using pGL2B activity as background, essentially as described (Rajas et al., 2002).

\section{Primary Hepatocyte isolation, culture and heme exposure}

Primary mouse hepatocytes were isolated, essentially as described (Dentin et al., 2004). Briefly, C57BL/6 mice were anesthetized (200 $\mu \mathrm{l} /$ mouse, i.p., consisting of $30 \mu \mathrm{l}$ Imalgene 1000; MERIAL \#915264 and $2 \mu$ I Rompun 2\%; Bayer \#7427831 in $\mathrm{ddH}_{2} \mathrm{O}$ ) and perfused with liver perfusion medium ( $25 \mathrm{~mL}$; Gibco; 5 minutes) followed by freshly prepared collagenase buffer (42.5 mL HBSS; Gibco; $5 \mathrm{~mL} 6.67 \mathrm{mM} \mathrm{CaCl}_{2}, 2.5$ $\mathrm{mL} 1 \mathrm{M}$ Hepes, 12mg Collagenase, Sigma; 8 minutes). The digested liver was dissected to obtain crude liver single cell suspensions and hepatocytes were resuspended in Percoll-based gradient $(9.6 \mathrm{ml}$; $0.96 \mathrm{~mL}$ PBS 10X; 8,64 mL Percoll; GE), centrifuged (50g; 10 minutes). Hepatocytes were seeded on pre-coated 6 well plates $(50 \mu \mathrm{g} / \mathrm{mL}$ rat collagen I, ThermoFisher in $20 \mathrm{mM}$ acetic acid) at a density of $3 \times 10^{5}$ cells per well in culture medium (William's E Medium; $5 \%$ FBS; $1 \%$ Penicillin/Streptomycin). Culture medium was replaced after 4 hours and cells were left untouched for 20 hours before adding fresh medium containing heme (10 $\mu \mathrm{M}$; Frontier Scientific, prepared in $\mathrm{NaOH}$ and neutralized with $\mathrm{HCl}$ ) and/or Dexamethasone (Sigma Aldrich; $100 \mathrm{mM}$ in 100\% Ethanol, diluted in ddH2O). Cells were rinsed with PBS and harvested for RNA extraction and analysis. 


\section{Serology}

Mice were sacrificed 7 days after Plasmodium infection and blood was collected for hemogram and serological analyses, performed by DNAtech (Portugal; http://www.dnatech.pt/web/).

\section{Histology}

Mice were sacrificed 7 days after Plasmodium infection, perfused in toto with ice-cold PBS and organs were harvested, fixed in $10 \%$ formalin, embedded in paraffin, sectioned $(3 \mu \mathrm{m})$ and stained with Hematoxylin \& Eosin (H\&E). Whole sections from formalin fixed and H\&E-stained tissues were analyzed. Slides were analyzed with a DMLB2 microscope (Leica), and images were acquired with a DFC320 camera (Leica) and NanoZoomer-SQ Digital slide scanner (Hamamatsu Photonics). Histology was analyzed at the Instituto Gulbenkian de Ciência Histopathology Unit. Images were analyzed and constructed using the NDP.view2 (Hamamatsu Photonics) software.

\section{Flow cytometry}

Mice were sacrificed, perfused in toto (PBS; $10 \mathrm{~mL}$ ) and spleens were collected in RMPI 1640, finely minced and passed through 70- and 40- $\mu$ m nylon meshes. RBCs were lysed (5min, RT) in RBC lysis buffer (9 parts of $0,16 \mathrm{M} \mathrm{NH}_{4} \mathrm{Cl} ;+1$ part $0,1 \mathrm{M}$ Tris HCL pH 7,5). Cells were collected, washed (2x; ice cold PBS) and incubated with Fc Block (anti-CD16/CD32, clone 2.4G2, produced in house; 15 min.; $4^{\circ} \mathrm{C}$ ) to prevent unspecific binding and with LIVE/DEADTM Fixable Yellow Dead Cell Stain Kit (Invitrogen ${ }^{\mathrm{TM}}$ ), excluding dead cells from analysis. Cells were washed (ice cold PBS) and stained $\left(20 \mathrm{~min}, 4^{\circ} \mathrm{C}\right)$ with fluorochrome-conjugated antibodies against: Ly6G (clone 1A8, PE-conjugated, BD Pharmingen ${ }^{\mathrm{TM}}$ ), TCR $\beta$ (clone H57-597; BV421conjugated, Biolegend), CD3 (clone 17A2; BV711-conjugated, Biolegend), NK1.1 (clone PK136; A647-conjugated, produced in house), CD4 (clone GK1.5, Pe/Cy7conjugated, Biolegend; or FITC-conjugated, produced in house), CD8 (clone 53-6.7; PercP/Cy5.5-conjugated, eBioscience ${ }^{\mathrm{TM}}$; or clone YTS169.4; PE-conjugated, produced in house), CD44 (clone IM7; eFluor 450-conjugated, eBioscience ${ }^{\mathrm{TM}}$ ), CD62L (clone Mel14; PercP/Cy5.5-conjugated, Biolegend), CD11b (clone M1/70, FITC-conjugated, BD Pharmingen ${ }^{\mathrm{TM}}$ ), CD19 (clone 6D5; BV711-conjugated, Biolegend), CD11c (clone N418; BV605-conjugated, Biolegend), F4/80 (clone BM8; 
A700-conjugated, Biolegend), CD163 (clone TNKUPJ; PercP-eFluor 710-conjugated, eBioscience $^{\mathrm{TM}}$ ) and CD169 (clone 3D6.112; A647-Conjugated, Biolegend). Antibodies produced in house were purified from the respective hybridoma and, if applicable, labeled at the IGC's Flow Cytometry and Antibodies Facility. Cells were analyzed on a LSR Fortessa X-20 (BD Biosciences). FACS data was analyzed with FlowJo V10.

For analysis of $P$. falciparum iRBC, Pf-3D7-GFP cultures were collected, washed (PBS) and stained with MitoTracker ${ }^{\mathrm{TM}}$ Deep Red FM (100nM in PBS; Invitrogen ${ }^{\mathrm{TM}}$, Thermo Fisher Scientific) for $15 \mathrm{~min}$. $37^{\circ} \mathrm{C}$. Cells were washed (PBS) again and stained with Hoechst 33342 (4mM in PBS; Thermo Fisher Scientific) for $15 \mathrm{~min}$. 37을 washed (PBS) and analyzed in a FACSAria ${ }^{\mathrm{TM}}$ llu Cell Sorter (BD Biosciences). FACS data was analyzed with FlowJo V10.

\section{Cytokines}

Mice were sacrificed 7 days after Pcc infection and plasma was collected from whole blood, for cytokine analyses, performed by Eve Technologies (Canada; https://www.evetechnologies.com/).

\section{Western Blots}

Proteins were extracted, electrophoresed and electro-transferred, essentially as previously described (Gozzelino et al., 2012; Ramos et al., 2019). Briefly, after euthanasia and perfusion (with ice-cold 1X PBS), livers were collected and snap frozen in liquid nitrogen. Tissue was lysed (2x SDS page sample buffer; 20\% glycerol, 4\% SDS, 100mM Tris pH6.8, 0.002\% bromophenol blue, and $100 \mathrm{mM}$ dithiothreitol) and homogenized in a tissue lyser (Qiagen) with tungsten carbide beads (Qiagen). Supernatants were collected and total protein was quantified ( $\lambda_{280 \mathrm{~nm}}$; Nanodrop 2000; ThermoFisher Scientific). Protein (100 $\mu \mathrm{g}$ ) was resolved on a $12 \%$ SDS-PAGE and transferred to Polyvinylidene fluoride (PVDF) membranes. Membranes were blocked with $5 \%$ milk (in 1X T-TBS), washed with $1 \times 1$ T-TBS and incubated with primary antibodies overnight $\left(4^{\circ} \mathrm{C}\right)$. Primary antibodies include antimouse G6PC1 (Rabbit, 1:5000)(Weis et al., 2017) and anti-GAPDH (Sicgen, Goat, 1:5000). Membranes were blocked (5\% milk in $1 \mathrm{X}$ T-TBS) and were incubated with corresponding peroxidase-conjugated secondary antibodies (Goat: Donkey anti-Goat IgG $(\mathrm{H}+\mathrm{L})$ Secondary Antibody, HRP \#PA1-28664; Rabbit: Goat anti-Rabbit IgG 
$(\mathrm{H}+\mathrm{L})$ Secondary Antibody, HRP \#31460, Mouse: Peroxidase AffiniPure Donkey Anti-Mouse IgG $(\mathrm{H}+\mathrm{L})$ \#715-035-150) for 1 hour at room temperature. Peroxidase activity was detected using SuperSignal ${ }^{\mathrm{TM}}$ West Pico PLUS Chemiluminescent Substrate (ThermoFisher Scientific). Blots were developed using Amersham Imager 680 (GE Healthcare), equipped with a Peltier cooled Fujifilm Super CCD. Densitometry analysis was performed with ImageJ (Rasband, W.S., ImageJ, U.S. $\mathrm{NIH}$, Bethesda, Maryland, USA, https://imagej.nih.gov/ij/,1997-2014), using only images without saturated pixels.

\section{RNA extraction and $q R T-P C R$}

Mice were sacrificed, perfused in toto (10mL ice-cold PBS) and organs were harvested, snap frozen in liquid nitrogen and stored at $-80^{\circ} \mathrm{C}$. Total RNA was extracted using tripleXtractor reagent (Grisp), chloroform (Merk) and with the NucleoSpin RNA kit (Machery-Nagel), according to manufacturer's instructions. When indicated, whole blood was collected into heparinized tubes and RNA extracted using the NucleoSpin RNA Blood kit (Machery-Nagel), according to the manufacturer's instructions. For mouse primary hepatocytes, cells were collected into tripleXtractor reagent (Grisp) and RNA was extracted using chlorophorm, isopropanol and ethanol, according to manufacturer's instructions. cDNA was synthesized (Transcriptor First Strand cDNA Synthesis Kit, Roche or with Xpert cDNA Synthesis Kit, Grisp) for SYBR Green (iTaq Universal SYBR Green Supermix, Bio-Rad) based qPCR on a QuantStudioTM 7 Flex Real-Time PCR System (Applied Biosystems). Relative gene expression was calculated using the $2^{-\triangle C T}$ method (relative number) using Acidic ribosomal phosphoprotein PO (Arbp0) as the housekeeping control gene for mouse gene or PCC 185 for parasite genes. For list of PCR primers, see key resource table.

\section{Bulk RNA sequencing and Analysis of liver samples.}

Livers were harvested from euthanized C57BL6 mice, 7 days after PcC AS infection (see Plasmodium infections), 15 hours after heme administration (i.p., $30 \mathrm{mg} / \mathrm{Kg} \mathrm{BW}$ ) or after overnight fasting (controls), grinded and snap frozen in liquid nitrogen and stored at $-80^{\circ} \mathrm{C}$. RNA was extracted, cleaned (RNeasy MinElute Cleanup Kit, Qiagen) and assessed for quality using Agilent Bioanalyzer 2100 (Agilent Technologies) in combination with the RNA 6000 pico kit (Agilent Technologies). Full-length cDNAs and sequencing libraries were generated following the SMART- 
Seq2 protocol, as previously described (Picelli et al., 2014). After quality control (Agilent Technologies), library preparation including cDNA 'tagmentation', PCRmediated adaptor addition and amplification of the adapted libraries was done following the Nextera library preparation protocol (Nextera XT DNA Library Preparation kit, Illumina), as previously described (Baym et al., 2015). Libraries were sequenced (NextSeq500 sequencing; Illumina) using $75 \mathrm{SE}$ high throughput kit. Sequence information was extracted in FastQ format, using Illumina's bcl2fastq v.2.19.1.403, producing around $29.10^{6}$ reads per sample. Library preparation and sequencing were optimized and performed at the Instituto Gulbenkian Ciência Genomics Unit.

The fastq reads were aligned against the mouse reference genome GRCm38 using the annotation GENCODE M25 to extract information about splice junctions (STAR; v.2.7.3a) (Dobin et al., 2013). FeatureCounts (v.2.0.1) was used to perform read summarization by assigning uniquely mapped reads to genomic features. Gene expression tables were imported into the $\mathrm{R}$ programming language and environment (v.3.6.3) to perform differential gene expression and functional enrichment analyses, as well as data visualization.

Differential gene expression was performed using the DESeq2 $\mathrm{R}$ package (v.1.31.11). Gene expression was modeled by $\sim$ Condition which included the following factor samples: Pcc infection $(n=4)$, Heme administration $(n=3)$ and Fasting $(n=4)$. Genes not expressed or expressed less than 10 counts across the 11 samples were removed resulting in 18,136 genes for downstream differential gene expression analysis. We subsequently ran the function DESeq which estimates the size factors (by estimateSizeFactors, dispersion (by estimateDispersions) and fits a binomial GLM fitting for $\beta i$ coefficient and Wald statistics (by nbinomWaldTest). Finally, the pairwise comparisons tested through contrasts with the function results, given the alpha of 0.05 , were: Pcc vs. Fasting and Heme vs. Fasting. In addition, the log2 fold change for each pairwise comparison was shrunken with the function lfcShrink using the algorithm ashr (v.2.2-47)(Liao et al., 2014)). Differentially expressed genes are genes with an adjusted $p$-value $<0.05$ and an absolute log2 fold change $>0$. Normalized gene expression counts were obtained with the function counts using the option normalized = TRUE. Regularized log transformed gene expression counts were obtained with rlog, using the option blind = TRUE, for Principal Component Analysis of overall sample expression profiles and for hierarchical clustering of differentially expressed genes. 
The Ensembl gene ids were converted into gene symbols from Ensembl (v.101 Aug 2020-https://aug2020.archive.ensembl.org) by using the mouse reference (GRCm38.p6) database with biomaRt $R$ package (v.2.46.2). All scatter plots, including volcano plots, were done with the ggplot2 R package (v.3.3.2). Venn diagrams were made with VennDiagram (v.1.6.20). Heatmaps were made with ComplexHeatmap (v.2.2.0), using the default options for distance and clustering method estimation.

Functional enrichment analysis was performed with the gprofiler2 $\mathrm{R}$ package (v.0.2.0). The function gost was applied in order to perform enrichment based on the list of up- or down-regulated genes (genes with an adjusted $p$-value $<0.05$ and a log2 fold-change $>0$ or $<0$ ), between each pairwise comparison (independently), against the annotated genes (domain_scope = "annotated") of the organism Mus musculus (organism = "mmusculus"). The gene lists were ordered by increasing adjusted $p$ value (ordered_query = TRUE) in order to generate a GSEA (Gene Set Enrichment Analysis) style p-values. In addition, only statistically significant (user_threshold=0.05) enriched functions are returned (significant=TRUE) after multiple testing corrections with the default method g:SCS (correction_method = "g_SCS"). gprofiler2 was run against all the default functional databases for mouse which include: Gene Ontology (GO:MF, GO:BP, GO:CC), KEGG (KEGG), Reactome (REAC), TRANSFAC (TF), miRTarBase (MIRNA), Human phenotype ontology (HP), WikiPathways (WP), CORUM (CORUM). gprofiler2 was with the archived version of the gprofiler2 server to ensure reproducibility - Ensembl 102, Ensembl Genomes 49 (database built on 2020-12-15): https://biit.cs.ut.ee/gprofiler_archive3/e102_eg49_p15/gost.

\section{Transcription factor binding motif prediction}

The -320 to +20 bp promoter region sequence of the mouse G6pc1 was entered into the JASPAR database (http://jaspar.genereg.net), a non-redundant set of transcription factor binding profiles derived from published datasets of transcription factors binding sites (Sandelin et al., 2004). The transcription factors SP1, SP3, KLF3, KLF5, KLF7, ZF5, E2F-1, E2F-3, E2F-4, KROX/EGR1, CTCF or WT1 and AhR were assessed for predicted binding sites. Candidate binding sites were identified with predicted motifs using a relative profile score threshold of $80 \%$ (i.e., the default JASPAR setting). Motif scores are JASPAR relative scores, which is defined as 1 for the maximum-likelihood sequence. 


\section{Single-cell RNA sequencing}

Blood was collected from $G 6 p C 1^{f / / f l}$ or $G 6 p c 1^{A l b \Delta / \Delta}$ mice at the peak of infection (i.e. day 7) with a transgenic PCC AS expressing GFP. Samples were diluted 1:7.5 in 1xPBS and iRBCs were sorted according FSC, SSC and GFP on a BD FACS Aria Ilu. Cells were washed twice with $1 \times$ PBS, counted, and adjusted to a concentration of 1200 cells $/ \mu \mathrm{L}$.

\section{Single-cell gene expression library preparation and sequencing}

Cell suspensions were processed with Chromium ${ }^{\mathrm{TM}}$ Single Cell Controller to generate barcoded single-cell gel bead emulsions (GEMs) following the Chromium Next GEM Single Cell $3 \square$ protocol. The single-cell cDNA libraries were obtained after the GEM-RT (reverse-transcriptase) clean-up and cDNA amplification on a Bio-Rad C1000 Touch $^{\mathrm{TM}}$ Thermal Cycler with the following PCR thermal program: 1) $98^{\circ} \mathrm{C}$ for $3 \mathrm{~min}, 2) 98{ }^{\circ} \mathrm{C}$ for $\left.15 \mathrm{sec}, 3\right) 63^{\circ} \mathrm{C}$ for $\left.20 \mathrm{sec}, 4\right) 72{ }^{\circ} \mathrm{C}$ for $1 \mathrm{~min}$, (Steps 2 to 4 cycled $11 \mathrm{x}$ ), 5) $72{ }^{\circ} \mathrm{C}$ for $1 \mathrm{~min}$ and 6) $4 \stackrel{\circ}{\circ} \mathrm{C}$ Hold. The cDNA profiles were checked on a Fragment Analyzer System (Agilent Technologies) according to the HS NGS Fragment kit (Agilent Technologies) manual. The scRNA-seq libraries were generated from $10 \mu \mathrm{l}(25 \%)$ of the single-cell cDNA sample and indexed with the Chromium i7 Multiplex Kit (10x Genomics) on a Bio-Rad C1000 Touch ${ }^{\text {TM }}$ Thermal Cycler as follows: 1) $98^{\circ} \mathrm{C}$ for $45 \mathrm{sec}$, 2) $98^{\circ} \mathrm{\circ}$ for $20 \mathrm{sec}$, 3) $54{ }^{\circ} \mathrm{C}$ for $30 \mathrm{sec}$, 4) 72 ${ }^{\circ} \mathrm{C}$ for $20 \mathrm{sec}$, (Steps 2 to 4 cycled $15 \mathrm{x}$ ), 5) $72{ }^{\circ} \mathrm{C}$ for $1 \mathrm{~min}$ and 6) $4 \stackrel{\circ}{\circ} \mathrm{C}$ Hold. The final 3' Gene Expression libraries were verified and quantified on a TapeStation 4200 using the D1000 ScreenTape kit (Agilent Technologies). Samples were sequenced on a NextSeq 500 (Illumina) using the NextSeq 500/550 High Output Kit v2.5 (150 Cycles) with the following sequencing run settings: Read1: 28cycles, i7 index: 8 cycles, i5 index 0 cycles, Read2: 130 cycles, aiming a read depth of $\sim 25,000$ reads/cell and.

\section{Single-cell RNA-seq raw data analysis}

Illumina sequencer base call files (BCL) were processed using Cell Ranger mkfastq pipeline generating FASTQ files. A custom genome reference was created for Plasmodium chabaudi following the steps described in https://support.10xgenomics.com/single-cell-geneexpression/software/pipelines/latest/using/tutorial_mr. Briefly a GTF file was created 
from the Plasmodium chabaudi GFF file and genome deposited at ftp://ftp.sanger.ac.uk/pub/genedb/releases/latest/Pchabaudi (retrieved on 2021, February 21) using the cellranger mkgtf command with the option to filter coding proteins. After, the reference genome was created by merging the GTF file with the genome of $P$. chabaudi in FASTA format using the cellranger mkref command. The two expression libraries were then analyzed with the Cell Ranger count pipeline v4.0.0 using the created $P$. chabaudi reference genome. All further analyses were performed using R (v. 3.6.3; R Core Team 2020). Samples were analyzed with the Seurat R package (v.4.0.0) (Butler et al., 2018; Hao et al., 2020; Satija et al., 2015) following the procedures of https://satijalab.org/seurat/articles/pbmc3k_tutorial.html. Samples were processed independently before integration as described https://satijalab.org/seurat/articles/integration_introduction.html. First, genes not expressed at least in 3 cells were removed as well as cells with a number of expressed genes higher and equal than 750 and a total number of reads higher or equal than 1500. These filters resulted in 4554 genes and 15537 cells for sample G6pc1 $1^{A l b \Delta / \Delta}$ and 4545 genes and 5176 cells in the case of sample G6pc $c^{10 x / 10 x}$. Both objects were normalized, variable features were determined, with the threshold of 750 most variable features and integrated features were selected. Integration was performed by finding shared anchors across the samples using the integrated variable features found before. The integrated Seurat object was re-scaled, PCA and UMAP were determined by using the first 12 principal components (PCs). Neighbors were found based on the first 12 PCs and PCA as the reduction method. Clustering was performed using the first 12 PCs and a resolution of 0.39 (based on the resolution used for the independent analysis of the sample of iRBCs of $G 6 p c 1^{A / b \Delta / \Delta}$ ), which yielded 9 clusters. The clusters were ascribed to different developmental stages of Pcc, according to the 25 highest conserved transcripts and by analogy to P. falciparum and P. berghei orthologues (Malaria Cell Atlas; https://www.sanger.ac.uk/tool/mca/). Differential expressed genes were identified using the Wilcoxon Rank Sum test and expression was analyzed across Pcc of iRBCs of $G 6 p c 1^{A l b \Delta / \Delta} v s$. G6pC1 $1^{f / f l}$ for each cluster. It was not possible to test differential gene expression for cluster 8 as this cluster is almost exclusive of Pcc of iRBCs of $G 6 p c 1^{A l b \Delta / \Delta}$. Functional enrichment analysis between the differentially expressed up- and down-regulated genes obtained from each pairwise comparison between each cluster across the two samples was performed by the use of gprofiler2 R package (v.0.2.0) (Kolberg et al., 2020)(an interface to the $\mathrm{g}$ :Profiler web browser tool using the archived version of the gprofiler2 server - Ensembl 102, Ensembl Genomes 49 (database built on 2020-12-15): 
https://biit.cs.ut.ee/gprofiler_archive3/e102_eg49_p15/gost. Enrichment was performed based on the list of up- or down-regulated genes, between each pairwise comparison (independently), against the annotated genes of the organism Plasmodium chabaudi available on the Gene Ontology database (GO:MF, GO:BP, $G O: C C)$. The gene lists were ordered by increasing adjusted $p$-value to generate a GSEA (Gene Set Enrichment Analysis) style $p$-values, following the same procedure described for Bulk RNA sequencing and analysis of liver samples. Functional enrichment was tested for all clusters, except for cluster 8 , as it lacks differential gene expression data. Genes were ranked up according to avg_log2FC $>0$ or down avg_log2FC $<0$. The ggplot2 R package was used for visualization (v.3.3.2) and the ComplexHeatmap package (v.2.2.0) for heatmaps.

For RNA-velocity a .loom file was created with the spliced and unspliced count matrices for each sample using the velocyto CLI tool (v.0.17.17)(La Manno et al., 2018) with the run10x command providing the previous GTF file of Pcc and the output of the Cell Ranger pipeline with the bam files and features matrix data. GNU parallel was used to run in parallel both samples (v.20161222). RNA velocity was estimated with the python package scvelo (v.0.2.2) using the stochastic model, and the velocities obtained were projected in the UMAP embeddings obtained previously with the Seurat software. Estimating RNA velocity from the spliced and unspliced matrices uses the ratio of spliced and unspliced RNA transcripts to determine the cell trajectories. Other packages used were os, random, anndata (v.0.7.5), pandas (v.1.1.3), numpy (v.1.19.2) and matplotlib (v.3.3.2) using python (v.3.8.3). This analysis is based on the tutorial: https://github.com/basilkhuder/Seurat-to-RNAVelocity.

Similarly to the above-described analysis of $P$. chabaudi, the reads of the murine RBCs were also analyzed to verify that similar amounts of cells were used for sequencing. In this case, the first 4 PCs were used for the computation of the UMAP. Downstream analysis of clusters was not performed.

\section{Data and Software availability}

Raw data files for the bulk and single cell RNA sequencing were deposited to BioStudies ArrayExpress database (https://www.ebi.ac.uk/arrayexpress/) with accession numbers E-MTAB-10935 (for liver bulk RNA) and E-MTAB-10939 (for single cell). 


\section{Statistical analysis.}

Statistically significant differences between two experimental groups were assessed using a two-tailed unpaired Mann-Whitney $U$ test or t-test. Comparisons between more than two groups were carried out by two-way ANOVA with Tukey's or Sidak's multiple-comparisons test, or Kruskal-Wallis test with Dunn's multiple-comparisons test. Survival was represented by Kaplan-Meier plots and difference between the groups was assessed using the log-rank test. All statistical analyses were performed using GraphPad Prism 8 software. Differences were considered significant at a $p$ value $<0.05$. ns: Not significant, $p>0.05 ;{ }^{*}: p<0.05,{ }^{* *}: p<0.01 ;{ }^{* * *}: p<0.001 ;{ }^{* * * *}$ : $\mathrm{p}<0.0001$.

\section{REFERENCES}

Ademolue, T.W., Amodu, O.K., and Awandare, G.A. (2017). Sickle cell trait is associated with controlled levels of heme and mild pro-inflammatory response during acute malaria infection. Clin Exp Immunol.

Arieff, A.I., Doerner, T., Zelig, H., and Massry, S.G. (1974). Mechanisms of Seizures and Coma in Hypoglycemia EVIDENCE FOR A DIRECT EFFECT OF INSULIN ON ELECTROLYTE TRANSPORT IN BRAIN. The Journal of Clinical Investigation 54, 654-663.

Babbitt, S.E., Altenhofen, L., Cobbold, S.A., Istvan, E.S., Fennell, C., Doerig, C., Llinás, M., and Goldberg, D.E. (2012). Plasmodium falciparum responds to amino acid starvation by entering into a hibernatory state. Proceedings of the National Academy of Sciences 109, E3278-E3287.

Baym, M., Kryazhimskiy, S., Lieberman, T.D., Chung, H., Desai, M.M., and Kishony, R. (2015). Inexpensive multiplexed library preparation for megabase-sized genomes. PLoS One 10, e0128036.

Bergen, V., Lange, M., Peidli, S., Wolf, F.A., and Theis, F.J. (2020). Generalizing RNA velocity to transient cell states through dynamical modeling. Nat Biotechnol 38 , 1408-1414.

Blankenhaus, B., Braza, F., Martins, R., Bastos-Amador, P., Gonzalez-Garcia, I., Carlos, A.R., Mahu, I., Faisca, P., Nunes, J.M., Ventura, P., et al. (2019). Ferritin regulates organismal energy balance and thermogenesis. Mol Metab.

Briquet, S., Lawson-Hogban, N., Boisson, B., Soares, M.P., Peronet, R., Smith, L., Menard, R., Huerre, M., Mecheri, S., and Vaquero, C. (2015). Disruption of Parasite hmgb2 Gene Attenuates Plasmodium berghei ANKA Pathogenicity. Infect Immun 83, 2771-2784.

Brugat, T., Reid, A.J., Lin, J.-w., Cunningham, D., Tumwine, I., Kushinga, G., McLaughlin, S., Spence, P., Böhme, U., Sanders, M., et al. (2017). Antibodyindependent mechanisms regulate the establishment of chronic Plasmodium infection. Nature Microbiology 2, 16276. 
Buck, M.D., Sowell, R.T., Kaech, S.M., and Pearce, E.L. (2017). Metabolic Instruction of Immunity. Cell 169, 570-586.

Butler, A., Hoffman, P., Smibert, P., Papalexi, E., and Satija, R. (2018). Integrating single-cell transcriptomic data across different conditions, technologies, and species. Nat Biotechnol 36, 411-420.

Clark, I.A., Budd, A.C., and Alleva, L.M. (2008). Sickness behaviour pushed too far the basis of the syndrome seen in severe protozoal, bacterial and viral diseases and post-trauma. Malaria Journal 7, 208.

Cruz, L.A.B., Barral-Netto, M., and Andrade, B.B. (2018). Distinct inflammatory profile underlies pathological increases in creatinine levels associated with Plasmodium vivax malaria clinical severity. PLoS Negl Trop Dis 12, e0006306.

Cui, A., Fan, H., Zhang, Y., Zhang, Y., Niu, D., Liu, S., Liu, Q., Ma, W., Shen, Z., Shen, L., et al. (2019). Dexamethasone-induced Krüppel-like factor 9 expression promotes hepatic gluconeogenesis and hyperglycemia. The Journal of Clinical Investigation 129, 2266-2278.

Cumnock, K., Gupta, A.S., Lissner, M., Chevee, V., Davis, N.M., and Schneider, D.S. (2018). Host Energy Source Is Important for Disease Tolerance to Malaria. Curr Biol 28, 1635-1642 e1633.

Dentin, R., Pégorier, J.-P., Benhamed, F., Foufelle, F., Ferré, P., Fauveau, V., Magnuson, M.A., Girard, J., and Postic, C. (2004). Hepatic Glucokinase Is Required for the Synergistic Action of ChREBP and SREBP-1c on Glycolytic and Lipogenic Gene Expression*. Journal of Biological Chemistry 279, 20314-20326.

Dobin, A., Davis, C.A., Schlesinger, F., Drenkow, J., Zaleski, C., Jha, S., Batut, P., Chaisson, M., and Gingeras, T.R. (2013). STAR: ultrafast universal RNA-seq aligner. Bioinformatics 29, 15-21.

Donnelly, R.P., Loftus, R.M., Keating, S.E., Liou, K.T., Biron, C.A., Gardiner, C.M., and Finlay, D.K. (2014). mTORC1-dependent metabolic reprogramming is a prerequisite for NK cell effector function. Journal of immunology (Baltimore, Md : 1950) $193,4477-4484$.

Dutra, F.F., and Bozza, M.T. (2014). Heme on innate immunity and inflammation. Front Pharmacol 5, 115.

Elased, K., and Playfair, J.H. (1994). Hypoglycemia and hyperinsulinemia in rodent models of severe malaria infection. Infect Immun 62, 5157-5160.

Elphinstone, R.E., Conroy, A.L., Hawkes, M., Hermann, L., Namasopo, S., Warren, H.S., John, C.C., Liles, W.C., and Kain, K.C. (2016). Alterations in Systemic Extracellular Heme and Hemopexin Are Associated With Adverse Clinical Outcomes in Ugandan Children With Severe Malaria. J Infect Dis 214, 1268-1275.

Enerbäck, S., Jacobsson, A., Simpson, E.M., Guerra, C., Yamashita, H., Harper, M.E., and Kozak, L.P. (1997). Mice lacking mitochondrial uncoupling protein are cold-sensitive but not obese. Nature 387, 90-94. 
Evans, S.S., Repasky, E.A., and Fisher, D.T. (2015). Fever and the thermal regulation of immunity: the immune system feels the heat. Nature Reviews Immunology 15, 335-349.

Ferreira, A., Balla, J., Jeney, V., Balla, G., and Soares, M.P. (2008). A central role for free heme in the pathogenesis of severe malaria: the missing link? J Mol Med 86, 1097-1111.

Ferreira, A., Marguti, I., Bechmann, I., Jeney, V., Chora, A., Palha, N.R., Rebelo, S., Henri, A., Beuzard, Y., and Soares, M.P. (2011). Sickle Hemoglobin Confers Tolerance to Plasmodium Infection. Cell 145, 398-409.

Francis, S.E., Sullivan, D.J., Jr., and Goldberg, D.E. (1997). Hemoglobin metabolism in the malaria parasite Plasmodium falciparum. Annu Rev Microbiol 51, 97-123.

Franklin, B.S., Parroche, P., Ataíde, M.A., Lauw, F., Ropert, C., de Oliveira, R.B., Pereira, D., Tada, M.S., Nogueira, P., da Silva, L.H., et al. (2009). Malaria primes the innate immune response due to interferon-gamma induced enhancement of toll-like receptor expression and function. Proc Natl Acad Sci U S A 106, 5789-5794.

Ganeshan, K., and Chawla, A. (2017). Warming the mouse to model human diseases. Nature Reviews Endocrinology 13, 458-465.

Ganeshan, K., Nikkanen, J., Man, K., Leong, Y.A., Sogawa, Y., Maschek, J.A., Van Ry, T., Chagwedera, D.N., Cox, J.E., and Chawla, A. (2019). Energetic Trade-Offs and Hypometabolic States Promote Disease Tolerance. Cell 177, 399-413 e312.

Geoffrion, Y., Butler, K., Pass, M., Smith, I.C.P., and Deslauriers, R. (1985). Plasmodium berghei: Gluconeogenesis in the infected mouse liver studied by $13 \mathrm{C}$ nuclear magnetic resonance. Experimental Parasitology 59, 364-374.

Gouveia, Z., Carlos, A.R., Yuan, X., Aires-da-Silva, F., Stocker, R., Maghzal, G.J., Leal, S.S., Gomes, C.M., Todorovic, S., Iranzo, O., et al. (2017). Characterization of plasma labile heme in hemolytic conditions. FEBS J 284, 3278-3301.

Gozzelino, R., Andrade, B.B., Larsen, R., Luz, N.F., Vanoaica, L., Seixas, E., Coutinho, A., Cardoso, S., Rebelo, S., Poli, M., et al. (2012). Metabolic adaptation to tissue iron overload confers tolerance to malaria. Cell Host Microbe 12, 693-704.

Hao, Y., Hao, S., Andersen-Nissen, E., Mauck, W.M., Zheng, S., Butler, A., Lee, M.J., Wilk, A.J., Darby, C., Zagar, M., et al. (2020). Integrated analysis of multimodal single-cell data. bioRxiv, 2020.2010.2012.335331.

Hart, B.L. (1988). Biological basis of the behavior of sick animals. Neurosci Biobehav Rev 12, 123-137.

Hebbel, R.P., Morgan, W.T., Eaton, J.W., and Hedlund, B.E. (1988). Accelerated autoxidation and heme loss due to instability of sickle hemoglobin. Proc Natl Acad Sci U S A 85, 237-241.

Hirako, I.C., Assis, P.A., Hojo-Souza, N.S., Reed, G., Nakaya, H., Golenbock, D.T., Coimbra, R.S., and Gazzinelli, R.T. (2018). Daily Rhythms of TNFalpha Expression and Food Intake Regulate Synchrony of Plasmodium Stages with the Host Circadian Cycle. Cell Host Microbe 23, 796-808 e796. 
Homewood, C.A. (1977). Carbohydrate metabolism of malarial parasites. Bull World Health Organ 55, 229-235.

Hughey, C.C., Wasserman, D.H., Lee-Young, R.S., and Lantier, L. (2014). Approach to assessing determinants of glucose homeostasis in the conscious mouse.

Mammalian Genome 25, 522-538.

Humeida, H., Pradel, G., Stich, A., and Krawinkel, M. (2011). The effect of glucose and insulin on in vitro proliferation of Plasmodium falciparum. Journal of Diabetology 2, 6-6.

Karnad, D.R., Nor, M.B.M., Richards, G.A., Baker, T., Amin, P., Council of the World Federation of Societies of, I., and Critical Care, M. (2018). Intensive care in severe malaria: Report from the task force on tropical diseases by the World Federation of Societies of Intensive and Critical Care Medicine. J Crit Care 43, 356-360.

Kawo, N.G., Msengi, A.E., Swai, A.B., Chuwa, L.M., Alberti, K.G., and McLarty, D.G. (1990). Specificity of hypoglycaemia for cerebral malaria in children. Lancet 336, 454-457.

Knackstedt, S.L., Georgiadou, A., Apel, F., Abu-Abed, U., Moxon, C.A., Cunnington, A.J., Raupach, B., Cunningham, D., Langhorne, J., Krüger, R., et al. (2019). Neutrophil extracellular traps drive inflammatory pathogenesis in malaria. Sci Immunol 4.

Kolberg, L., Raudvere, U., Kuzmin, I., Vilo, J., and Peterson, H. (2020). gprofiler2 -an $\mathrm{R}$ package for gene list functional enrichment analysis and namespace conversion toolset g:Profiler. F1000Research 9.

Kumar, M., Skillman, K., and Duraisingh, M.T. (2021). Linking nutrient sensing and gene expression in Plasmodium falciparum blood-stage parasites. Mol Microbiol 115, 891-900.

La Manno, G., Soldatov, R., Zeisel, A., Braun, E., Hochgerner, H., Petukhov, V., Lidschreiber, K., Kastriti, M.E., Lönnerberg, P., Furlan, A., et al. (2018). RNA velocity of single cells. Nature 560, 494-498.

Liao, Y., Smyth, G.K., and Shi, W. (2014). featureCounts: an efficient general purpose program for assigning sequence reads to genomic features. Bioinformatics 30, 923-930.

Lobo, L., Cabral, L.I.L., Sena, M.I., Guerreiro, B., Rodrigues, A.S., de Andrade-Neto, V.F., Cristiano, M.L.S., and Nogueira, F. (2018). New endoperoxides highly active in vivo and in vitro against artemisinin-resistant Plasmodium falciparum. Malar $\mathrm{J} 17$, 145.

Mackinnon, M.J., and Read, A.F. (1999). GENETIC RELATIONSHIPS BETWEEN PARASITE VIRULENCE AND TRANSMISSION IN THE RODENT MALARIA PLASMODIUM CHABAUDI. Evolution 53, 689-703.

MacRae, J.I., Dixon, M.W., Dearnley, M.K., Chua, H.H., Chambers, J.M., Kenny, S., Bottova, I., Tilley, L., and McConville, M.J. (2013). Mitochondrial metabolism of sexual and asexual blood stages of the malaria parasite Plasmodium falciparum. BMC Biol 11, 67. 
Madrid, L., Lanaspa, M., Maculuve, S.A., and Bassat, Q. (2015). Malaria-associated hypoglycaemia in children. Expert Review of Anti-infective Therapy 13, 267-277.

Madrid, L., Sitoe, A., Varo, R., Nhampossa, T., Lanaspa, M., Nhama, A., Acácio, S., Riaño, I., Casellas, A., and Bassat, Q. (2017). Continuous determination of blood glucose in children admitted with malaria in a rural hospital in Mozambique. Malaria Journal 16, 184.

Man, K., Kutyavin, V.I., and Chawla, A. (2017). Tissue Immunometabolism: Development, Physiology, and Pathobiology. Cell Metab 25, 11-26.

Mancio-Silva, L., Slavic, K., Grilo Ruivo, M.T., Grosso, A.R., Modrzynska, K.K., Vera, I.M., Sales-Dias, J., Gomes, A.R., MacPherson, C.R., Crozet, P., et al. (2017). Nutrient sensing modulates malaria parasite virulence. Nature 547, 213-216.

Marr, E., Milne, R., Anar, B., Girling, G., Schwach, F., Mooney, J., Nahrendorf, W., Spence, P., Cunningham, D., Baker, D., et al. (2020). An enhanced toolkit for the generation of knockout and marker-free fluorescent Plasmodium chabaudi [version 2; peer review: 2 approved]. Wellcome Open Research 5.

Marsh, K., Forster, D., Waruiru, C., Mwangi, I., Winstanley, M., Marsh, V., Newton, C., Winstanley, P., Warn, P., Peshu, N., et al. (1995). Indicators of life-threatening malaria in African children. N Engl J Med 332, 1399-1404.

Meireles, P., Sales-Dias, J., Andrade, C.M., Mello-Vieira, J., Mancio-Silva, L., Simas, J.P., Staines, H.M., and Prudencio, M. (2017). GLUT1-mediated glucose uptake plays a crucial role during Plasmodium hepatic infection. Cell Microbiol 19.

Miller, L.H., Baruch, D.I., Marsh, K., and Doumbo, O.K. (2002). The pathogenic basis of malaria. Nature $415,673-679$.

Mutel, E., Abdul-Wahed, A., Ramamonjisoa, N., Stefanutti, A., Houberdon, I., Cavassila, S., Pilleul, F., Beuf, O., Gautier-Stein, A., Penhoat, A., et al. (2011). Targeted deletion of liver glucose- 6 phosphatase mimics glycogen storage disease type 1a including development of multiple adenomas. J Hepatol 54, 529-537.

Negoro, H., Okinami, T., Kanematsu, A., Imamura, M., Tabata, Y., and Ogawa, O. (2013). Role of Rev-erba domains for transactivation of the connexin43 promoter with Sp1. FEBS Lett 587, 98-103.

Nunez, G., Sakamoto, K., and Soares, M.P. (2018). Innate Nutritional Immunity. J Immunol 201, 11-18.

Olszewski, K.L., and Llinas, M. (2011). Central carbon metabolism of Plasmodium parasites. Mol Biochem Parasitol 175, 95-103.

Pamplona, A., Ferreira, A., Balla, J., Jeney, V., Balla, G., Epiphanio, S., Chora, A., Rodrigues, C.D., Gregoire, I.P., Cunha-Rodrigues, M., et al. (2007). Heme oxygenase- 1 and carbon monoxide suppress the pathogenesis of experimental cerebral malaria. Nat Med 13, 703-710.

Pearce, E.L., Poffenberger, M.C., Chang, C.H., and Jones, R.G. (2013). Fueling immunity: insights into metabolism and lymphocyte function. Science 342, 1242454. 
Picelli, S., Faridani, O.R., Björklund, Å.K., Winberg, G., Sagasser, S., and Sandberg, R. (2014). Full-length RNA-seq from single cells using Smart-seq2. Nature Protocols 9, 171-181.

Preuss, J., Jortzik, E., and Becker, K. (2012a). Glucose-6-phosphate metabolism in Plasmodium falciparum. IUBMB Life 64, 603-611.

Preuss, J., Jortzik, E., and Becker, K. (2012b). Glucose-6-phosphate metabolism in Plasmodium falciparum. IUBMB life 64, 603-611.

Raghuram, S., Stayrook, K.R., Huang, P., Rogers, P.M., Nosie, A.K., McClure, D.B., Burris, L.L., Khorasanizadeh, S., Burris, T.P., and Rastinejad, F. (2007). Identification of heme as the ligand for the orphan nuclear receptors REV-ERBalpha and REVERBbeta. Nat Struct Mol Biol 14, 1207-1213.

Rajas, F., Gautier, A., Bady, I., Montano, S., and Mithieux, G. (2002).

Polyunsaturated fatty acyl coenzyme A suppress the glucose-6-phosphatase promoter activity by modulating the DNA binding of hepatocyte nuclear factor 4 alpha. J Biol Chem 277, 15736-15744.

Ramos, S., Carlos, A.R., Sundaram, B., Jeney, V., Ribeiro, A., Gozzelino, R., Bank, C., Gjini, E., Braza, F., Martins, R., et al. (2019). Renal control of disease tolerance to malaria. Proc Natl Acad Sci U S A 116, 5681-5686.

Rao, S., Schieber, A.M.P., O'Connor, C.P., Leblanc, M., Michel, D., and Ayres, J.S. (2017). Pathogen-Mediated Inhibition of Anorexia Promotes Host Survival and Transmission. Cell 168, 503-516 e512.

Reece, S.E., and Thompson, J. (2008). Transformation of the rodent malaria parasite Plasmodium chabaudi and generation of a stable fluorescent line PcGFPCON. Malaria Journal 7, 183.

Rojas, M.O., and Wasserman, M. (1993). Effect of Low Temperature On the In Vitro Growth of Plasmodium falciparum. Journal of Eukaryotic Microbiology 40, 149-152.

Salcedo-Sora, J.E., Caamano-Gutierrez, E., Ward, S.A., and Biagini, G.A. (2014). The proliferating cell hypothesis: a metabolic framework for Plasmodium growth and development. Trends Parasitol 30, 170-175.

Sandelin, A., Alkema, W., Engström, P., Wasserman, W.W., and Lenhard, B. (2004). JASPAR: an open-access database for eukaryotic transcription factor binding profiles. Nucleic Acids Res 32, D91-94.

Santos, S.A., Lukens, A.K., Coelho, L., Nogueira, F., Wirth, D.F., Mazitschek, R., Moreira, R., and Paulo, A. (2015). Exploring the 3-piperidin-4-yl-1H-indole scaffold as a novel antimalarial chemotype. European journal of medicinal chemistry 102, $320-$ 333.

Satija, R., Farrell, J.A., Gennert, D., Schier, A.F., and Regev, A. (2015). Spatial reconstruction of single-cell gene expression data. Nat Biotechnol 33, 495-502.

Schieber, A.M., and Ayres, J.S. (2016). Thermoregulation as a disease tolerance defense strategy. Pathog Dis 74. 
Schneider, D.S. (2011). Tracing personalized health curves during infections. PLoS Biol 9, e1001158.

Seixas, E., Gozzelino, R., Chora, A., Ferreira, A., Silva, G., Larsen, R., Rebelo, S., Penido, C., Smith, N.R., Coutinho, A., et al. (2009). Heme oxygenase-1 affords protection against noncerebral forms of severe malaria. Proc Natl Acad Sci U S A 106, 15837-15842.

Service, F.J. (1995). Hypoglycemic disorders. N Engl J Med 332, 1144-1152.

Sigala, P.A., and Goldberg, D.E. (2014). The peculiarities and paradoxes of Plasmodium heme metabolism. Annu Rev Microbiol 68, 259-278.

Soares, M.P., and Bozza, M.T. (2016). Red alert: labile heme is an alarmin. Curr Opin Immunol 38, 94-100.

Srivastava, A., Philip, N., Hughes, K.R., Georgiou, K., MacRae, J.I., Barrett, M.P., Creek, D.J., McConville, M.J., and Waters, A.P. (2016). Stage-Specific Changes in Plasmodium Metabolism Required for Differentiation and Adaptation to Different Host and Vector Environments. PLoS Pathog 12, e1006094.

Stearns, S.C., and Medzhitov, R. (2015). Evolutionary Medicine, 1st Edition edn (Oxford University press).

Su, Z., and Stevenson, M.M. (2000). Central role of endogenous gamma interferon in protective immunity against blood-stage Plasmodium chabaudi AS infection. Infect Immun 68, 4399-4406.

Thien, H.V., Kager, P.A., and Sauerwein, H.P. (2006). Hypoglycemia in falciparum malaria: is fasting an unrecognized and insufficiently emphasized risk factor? Trends Parasitol 22, 410-415.

Vandermosten, L., Pham, T.T., Knoops, S., De Geest, C., Lays, N., Van der Molen, K., Kenyon, C.J., Verma, M., Chapman, K.E., Schuit, F., et al. (2018). Adrenal hormones mediate disease tolerance in malaria. Nat Commun 9, 4525.

Wang, A., Huen, S.C., Luan, H.H., Baker, K., Rinder, H., Booth, C.J., and Medzhitov, R. (2018). Glucose metabolism mediates disease tolerance in cerebral malaria. Proc Natl Acad Sci U S A 115, 11042-11047.

Wang, A., Luan, H.H., and Medzhitov, R. (2019). An evolutionary perspective on immunometabolism. Science 363.

Wasner, C., Grempler, R., Walther, R., and Schmoll, D. (2001). Basal level glucose6-phosphatase gene transcription requires binding sites for Sp family proteins within the gene promoter. Biochimica et Biophysica Acta (BBA) - Gene Structure and Expression 1521, 126-129.

Weir, J.B.d.V. (1949). New methods for calculating metabolic rate with special reference to protein metabolism. The Journal of Physiology 109, 1-9.

Weis, S., Carlos, A.R., Moita, M.R., Singh, S., Blankenhaus, B., Cardoso, S., Larsen, R., Rebelo, S., Schäuble, S., Del Barrio, L., et al. (2017). Metabolic adaptation establishes disease tolerance to sepsis. Cell 169, 1263-1275. 
White, N.J., Warrell, D.A., Chanthavanich, P., Looareesuwan, S., Warrell, M.J., Krishna, S., Williamson, D.H., and Turner, R.C. (1983). Severe hypoglycemia and hyperinsulinemia in falciparum malaria. N Engl J Med 309, 61-66.

Yin, L., Wu, N., Curtin, J.C., Qatanani, M., Szwergold, N.R., Reid, R.A., Waitt, G.M., Parks, D.J., Pearce, K.H., Wisely, G.B., et al. (2007). Rev-erbalpha, a heme sensor that coordinates metabolic and circadian pathways. Science 318, 1786-1789.

Yuda, M., Iwanaga, S., Kaneko, I., and Kato, T. (2015). Global transcriptional repression: An initial and essential step for $<$ em $>$ Plasmodium $</$ em $>$ sexual development. Proceedings of the National Academy of Sciences 112, 12824-12829.

Zhang, Y., Fang, B., Emmett, M.J., Damle, M., Sun, Z., Feng, D., Armour, S.M., Remsberg, J.R., Jager, J., Soccio, R.E., et al. (2015). GENE REGULATION. Discrete functions of nuclear receptor Rev-erbalpha couple metabolism to the clock. Science 348, 1488-1492. 

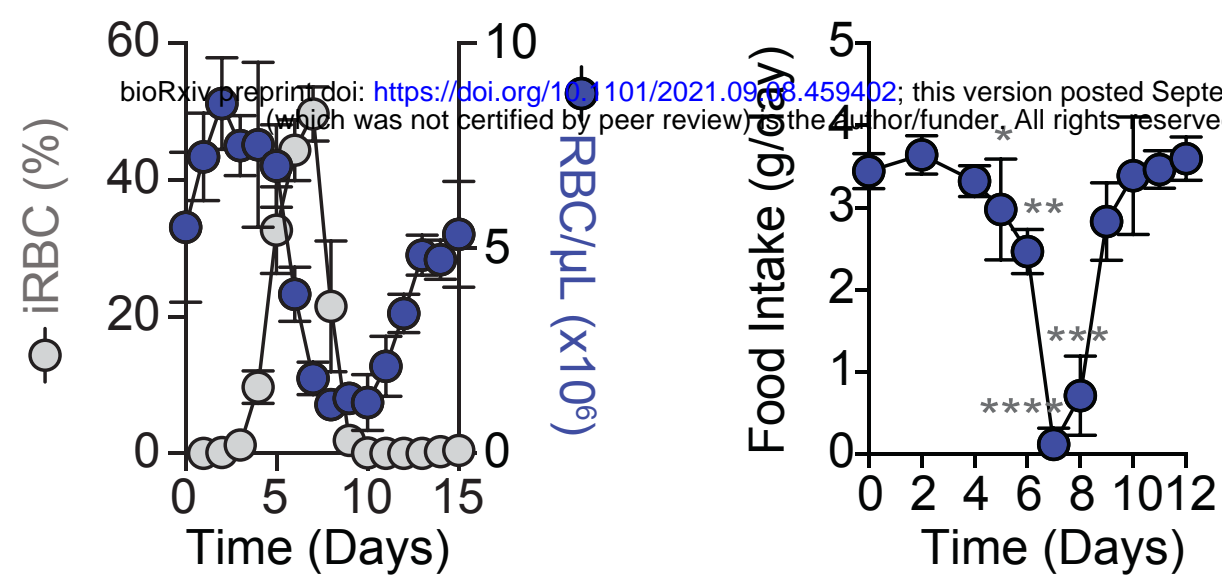

200

D

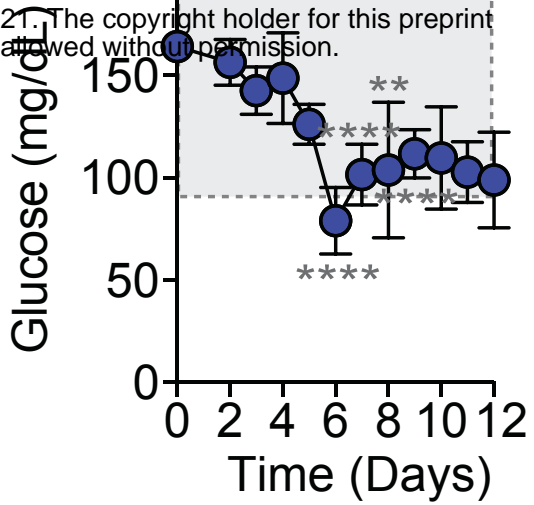

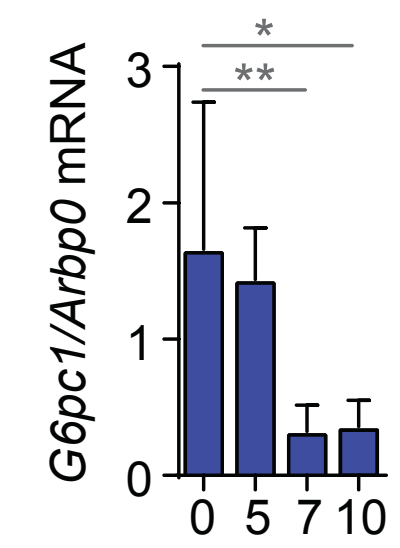

Time (Days)
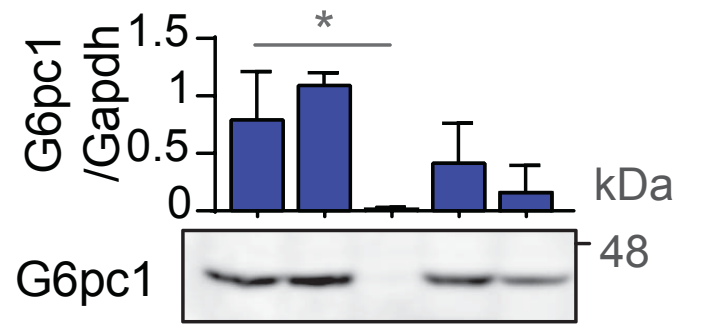

Gapdh

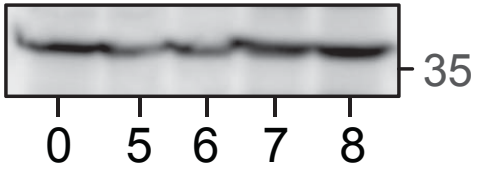

Time (Days) -o- Control -o-Pcc

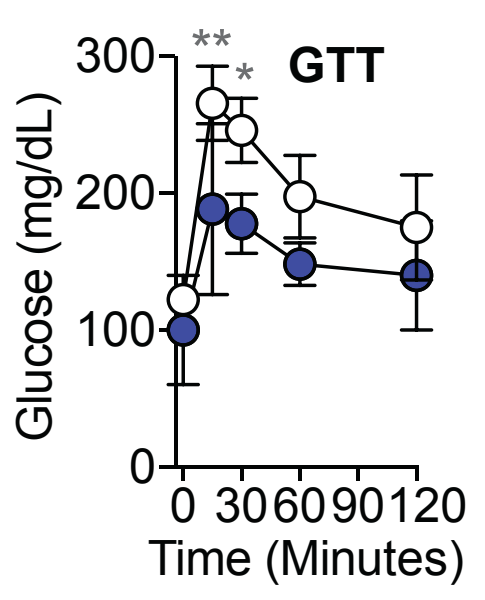

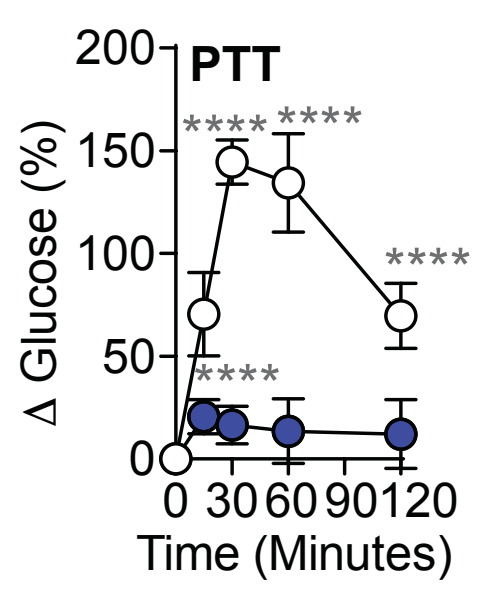

-o-Control -o-Pcc

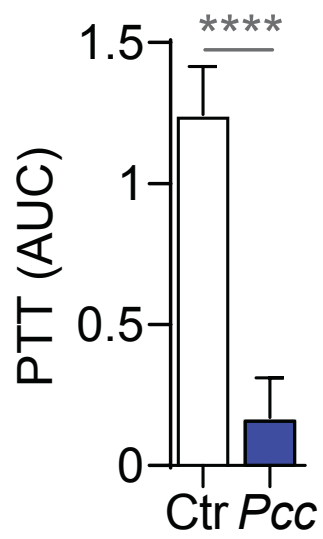

G
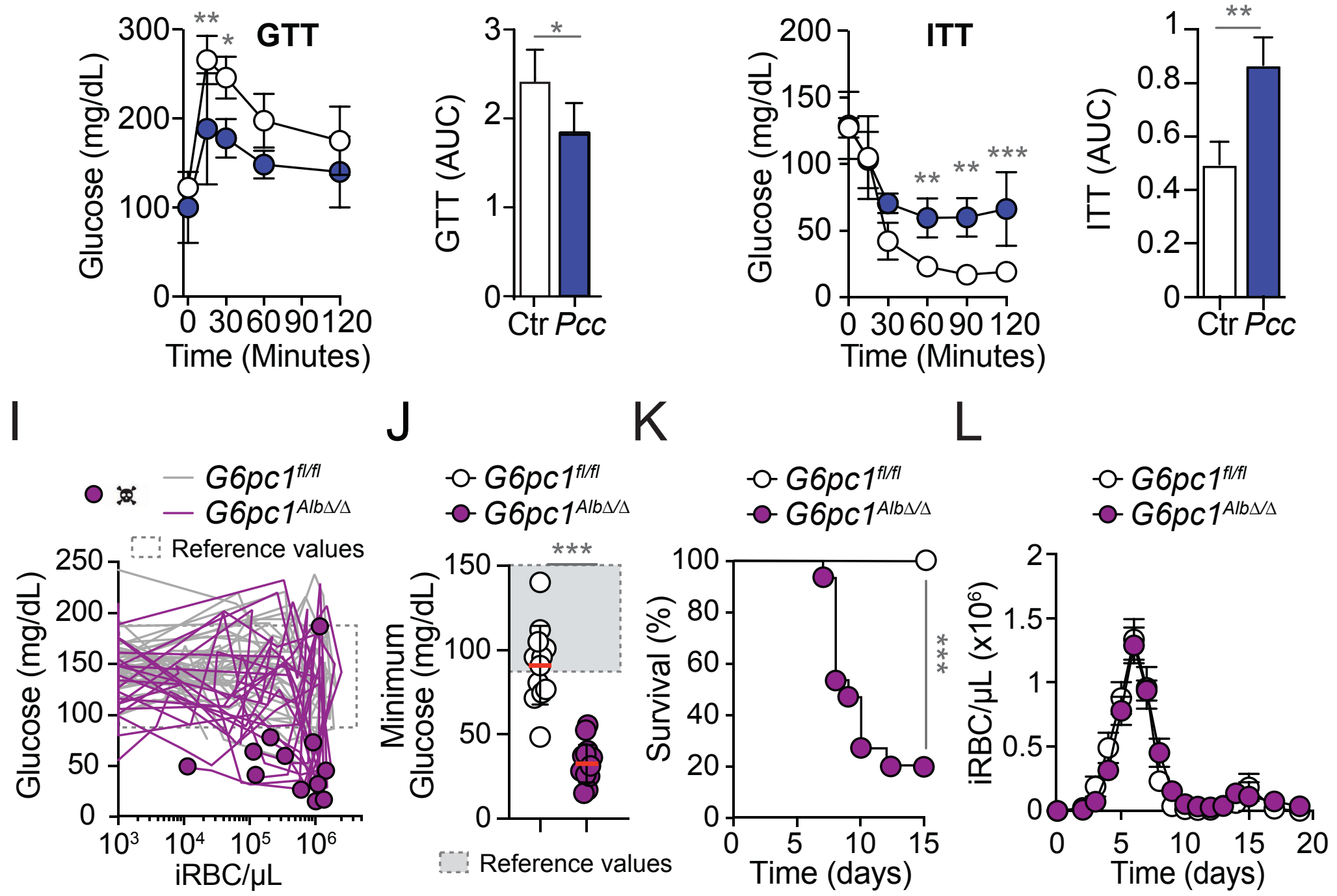


\section{$A$ \\ Fasting Heme Pcc \\ Differentially expressed}

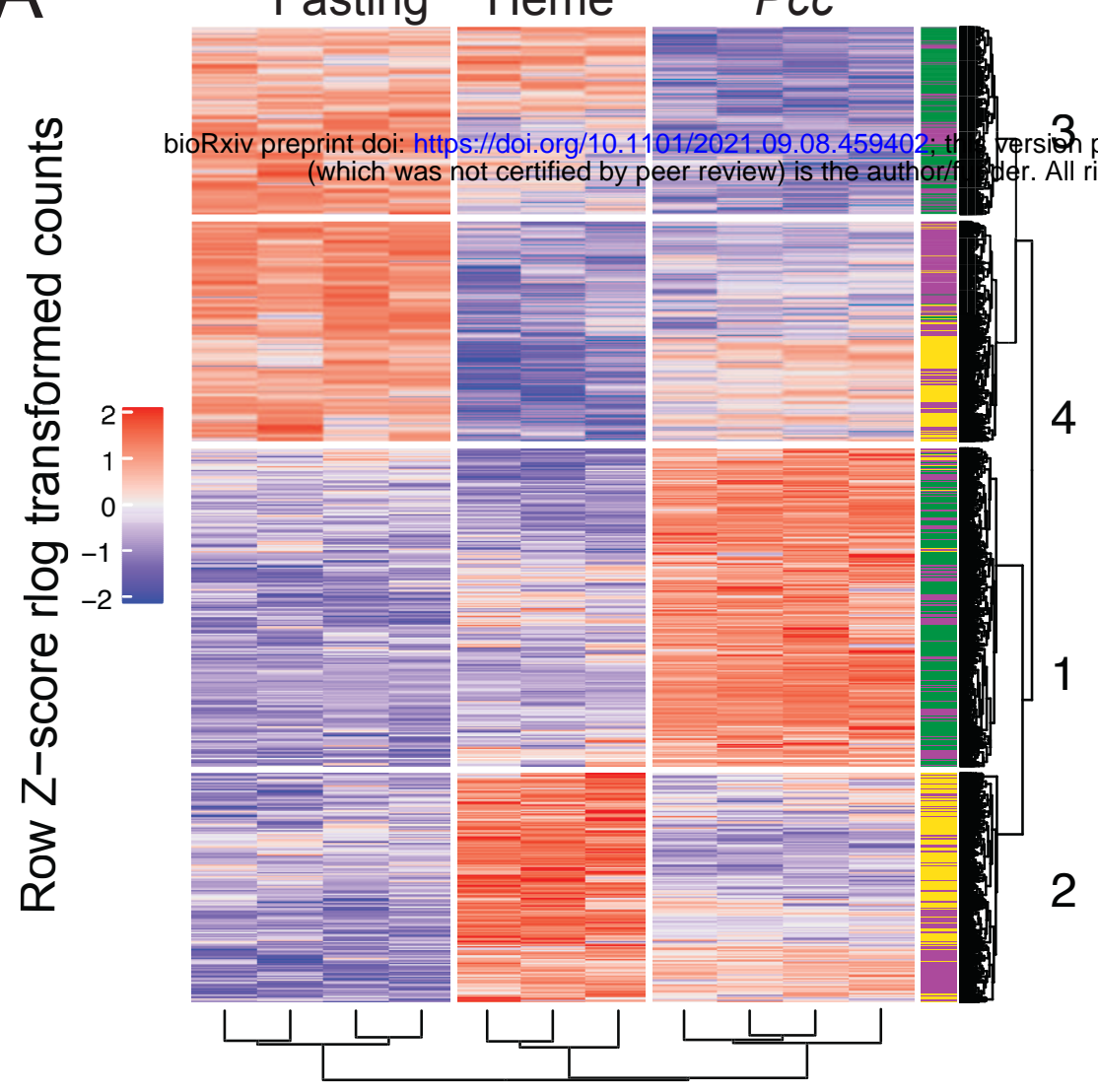

$\square$ Heme-specific $\square$ Pcc-specific $\square$ Shared

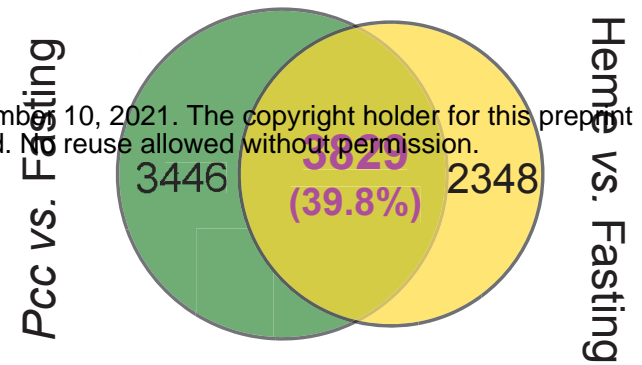

4

Upregulated

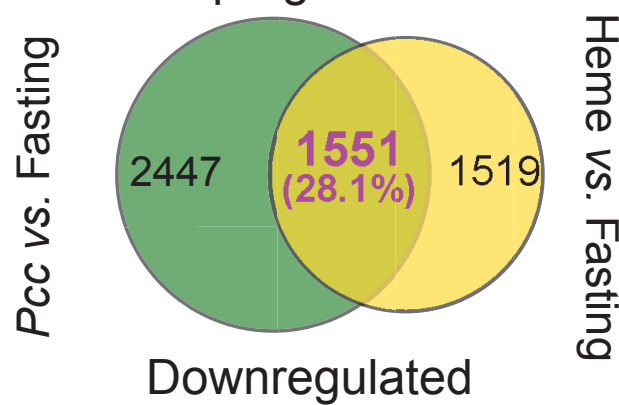

2

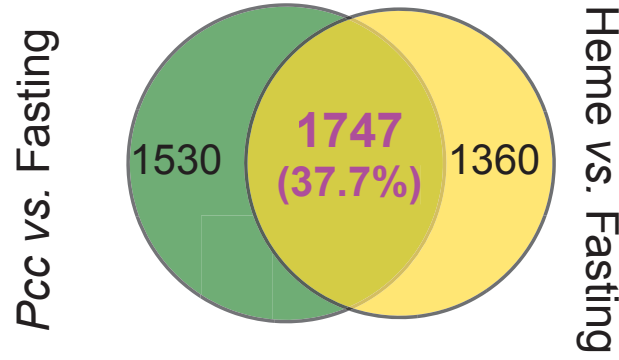

$\square$ Ctr. $\square$ Heme $\square$ PcC
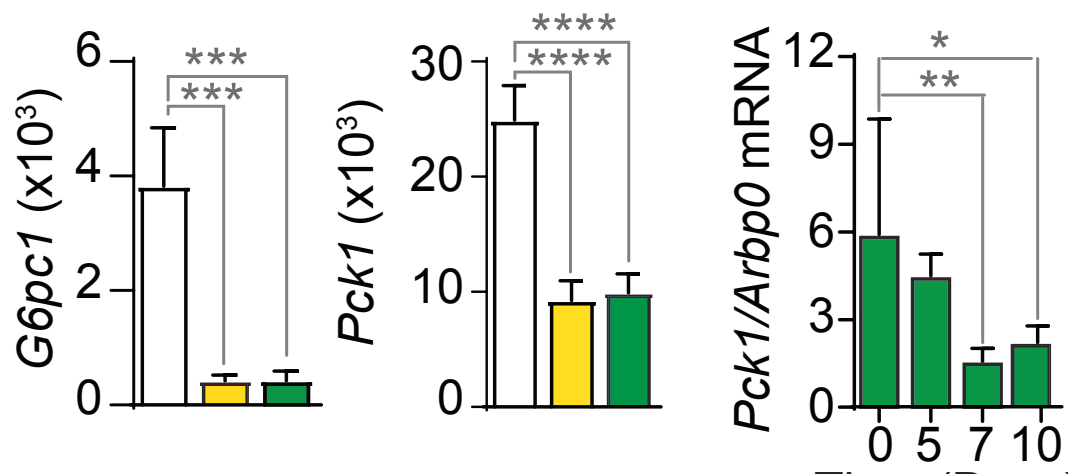

Time (Days)

$\square$ Heme vs. Fasting

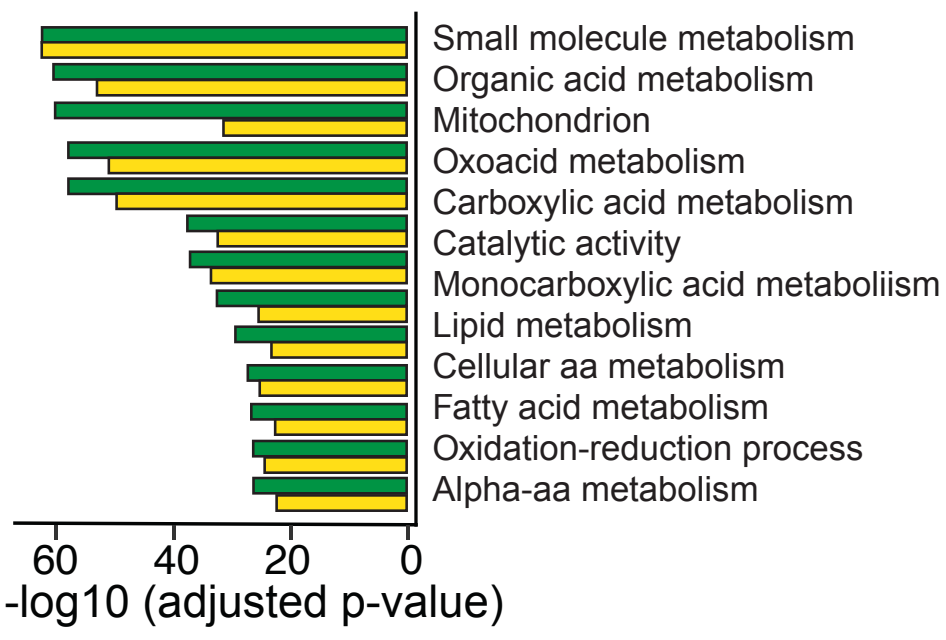

G

$\mathrm{H}$

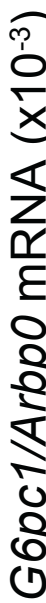
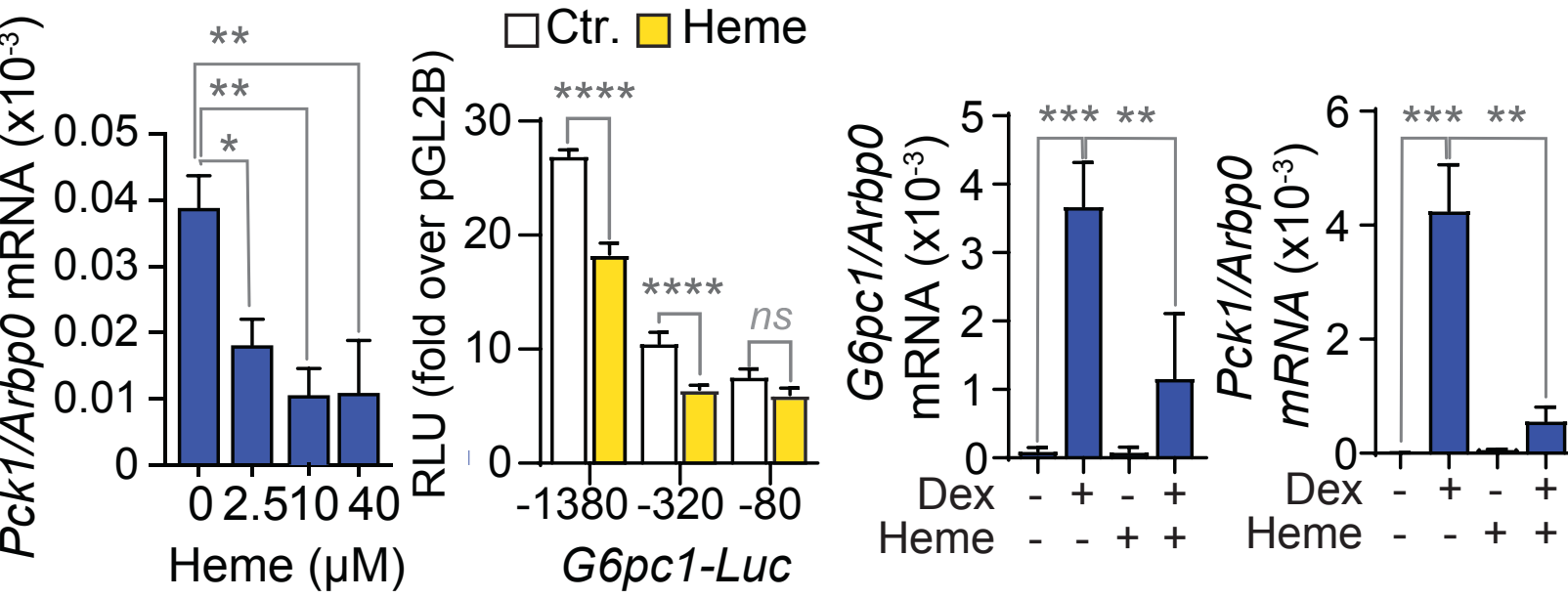
Heme ( $\mu \mathrm{M})$

Pcc vs. Fasting 
A $B$

G6pc1 $1^{f / f t} \quad G 6 p c 1^{A / b \Delta / \Delta}$
$-o-G 6 p c 1^{1 / / f I}-\circ G 6 p c 1^{A / b \Delta / \Delta}$

C $-0-G 6 p c 1^{f / f / t}$

ns

- $-G 6 p c 1^{A l b \Delta \Delta}$

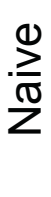

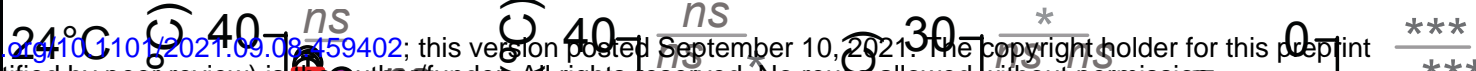

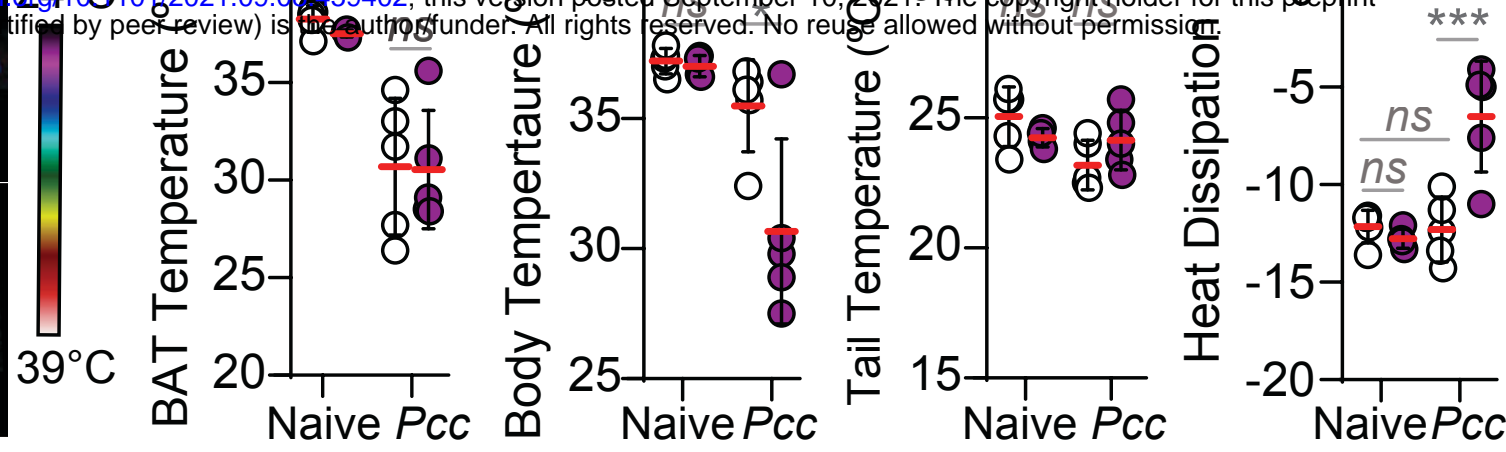

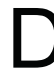

E

$F$

$G$

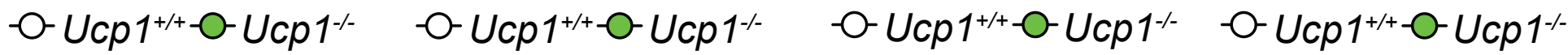
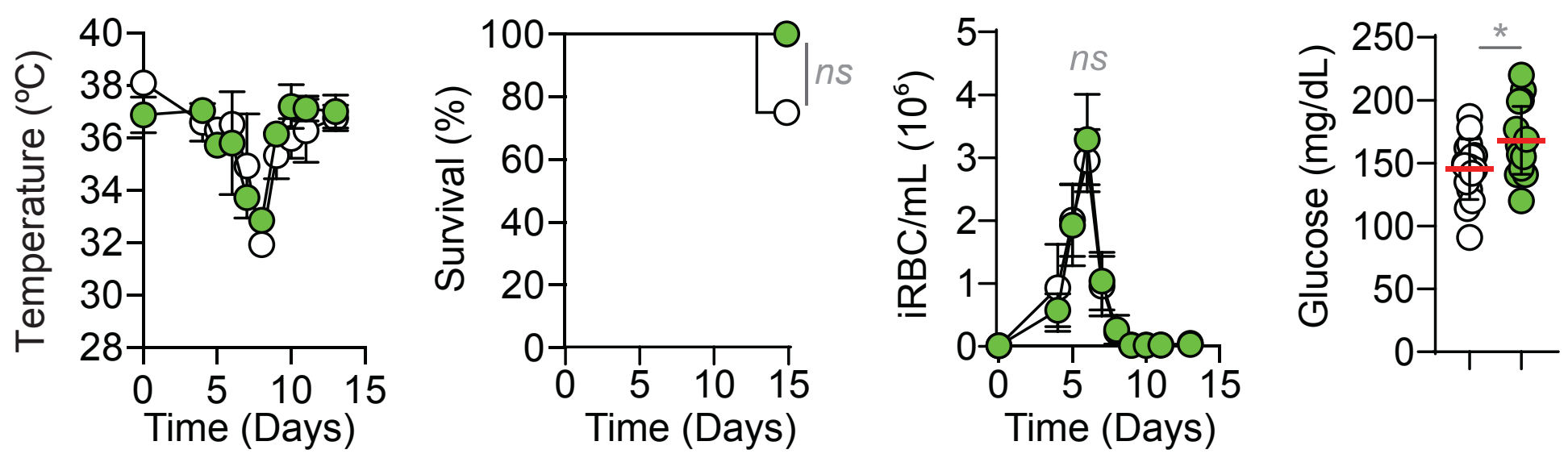

$\mathrm{H}$

$-0-22^{\circ} \mathrm{C}-0-31-32^{\circ} \mathrm{C}$

(1) $-0-22^{\circ} \mathrm{C}-0-31-32^{\circ} \mathrm{C}$

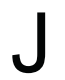

$\begin{array}{rlllll}24 & 1 & 1 & 1 & 1 & 1\end{array}$

Time (Days)
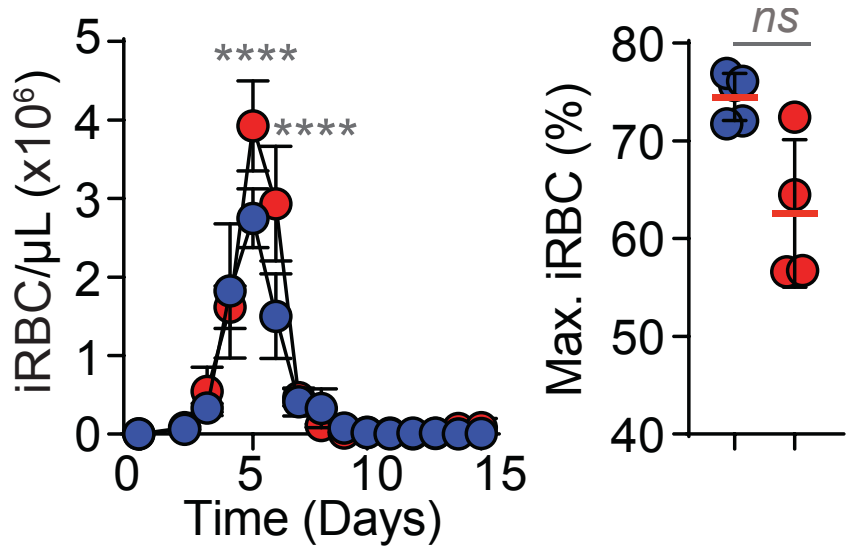

$-22^{\circ} \mathrm{C}-0-31-32^{\circ} \mathrm{C}$

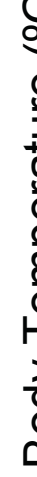

$-0-22^{\circ} \mathrm{C}-\mathrm{O}-31-32^{\circ} \mathrm{C}$

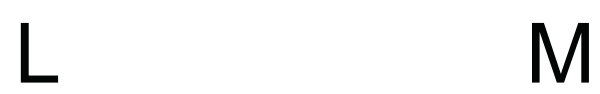

c

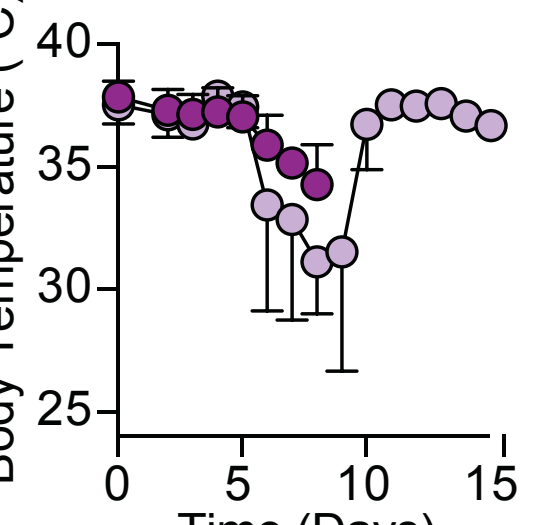

$-22^{\circ} \mathrm{C}-0-31-32^{\circ} \mathrm{C}$

M

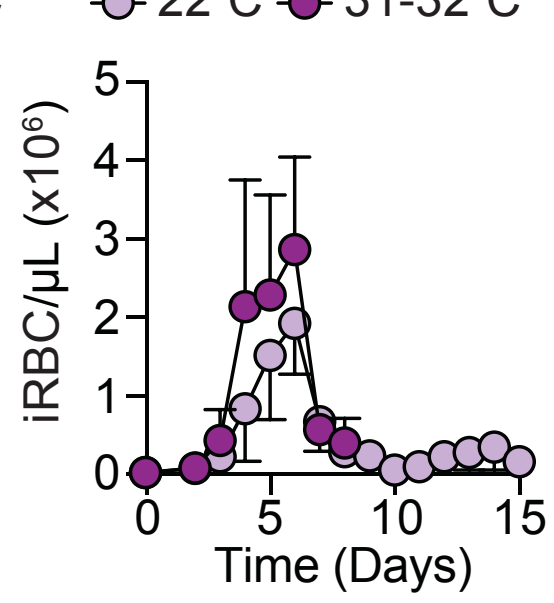

$-22^{\circ} \mathrm{C}$

$31-32^{\circ} \mathrm{C}$
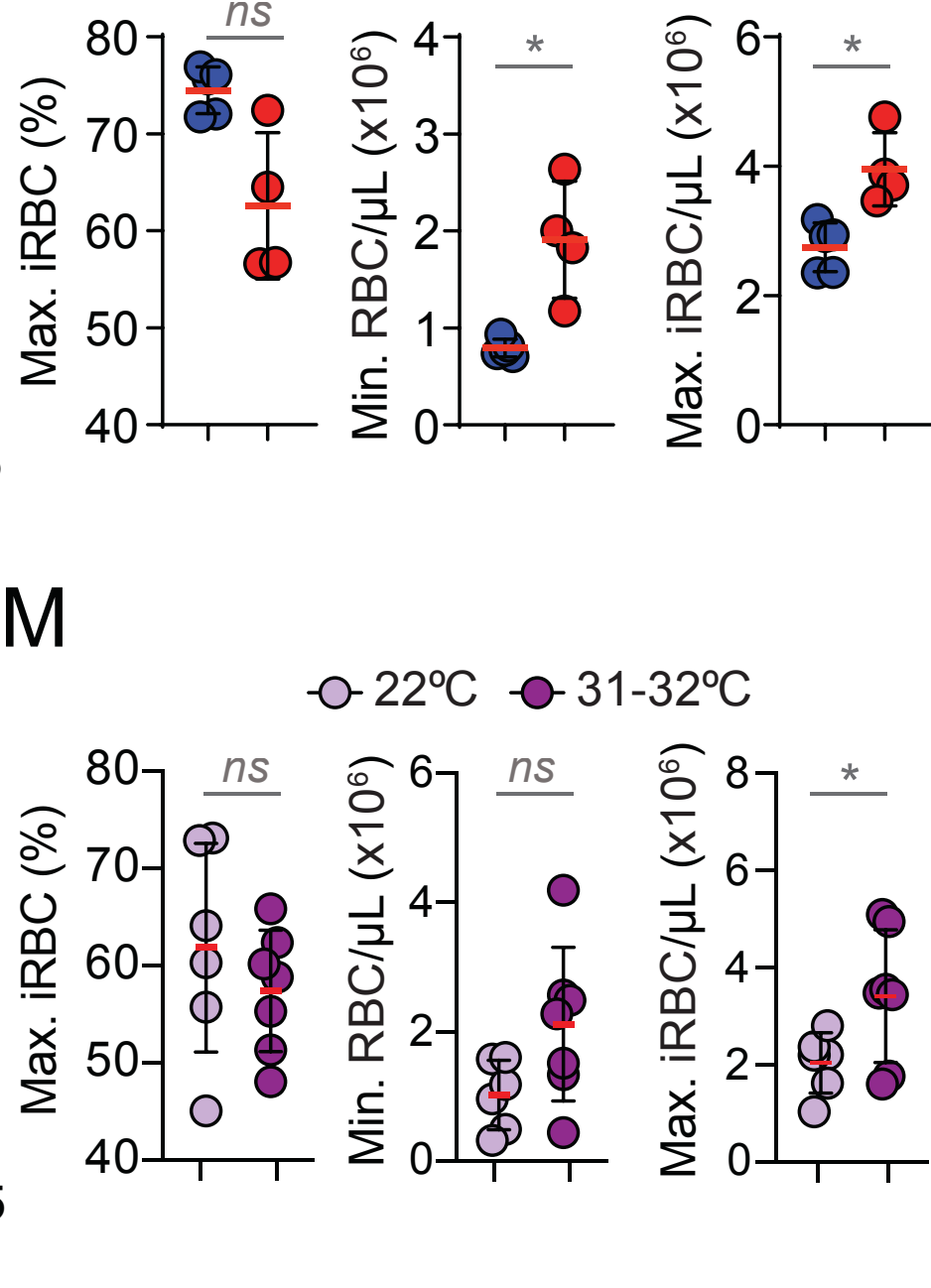

Time (Days) 